\title{
Escuchar las paredes del liceo: hermenéutica del graffiti *
}

Lourdes García Aguirre**

"Las paredes tienen orejas, sus orejas tienen paredes".

(Graffiti, 1968, Mayo francés)

\section{Resumen}

El propósito general de esta investigación ha sido identificar y analizar las interpretaciones que realizan los profesores y los estudiantes sobre el graffiti en el liceo ${ }^{1}$. Se enmarca en un enfoque hermenéutico y narrativo.

La metodología adoptada es cualitativa exploratoria, y biográfico-narrativa. Las técnicas elegidas fueron las siguientes: fotografía, entrevistas en profundidad a docentes y alumnos, y grupos de discusión.

De la investigación surgieron algunas categorías interpretativas: "el tren", "el juego", "la firma", "la red social”, "el grito", “la fobia", "lo político", "fuera de actas", "el deporte", "el hostigamiento". También se abordaron las siguientes cuestiones: la relación entre las tribus urbanas y el graffiti; los móviles de los que surgiría la necesidad de graffitear; por qué los docentes no "ven" los graffitis, y qué se ha hecho en los liceos con los mismos. Este artículo expone las categorías resultantes.

\section{Abstract}

The general purpose of this research has been to identify the interpretations of teachers and students of graffiti at high school facilities.

Throughout said research, its author has applied a qualitative, exploratory, and biographicnarrative methodology. The chosen techniques were photography, profound interviews with teachers and students, and focus groups.

From the research several categories have emerged such as "the train", "the play", "the signature", "the social network", "the shout", "the phobia", "politics", "off the record", "the sport" and "bullying". The following issues have also been approached: the relationship between urban tribes and graffiti; what leads students to graffiti at educational centres; why teachers "do not see" the graffiti, and what has been done in high schools with latter. This article displays the categories that resulted from the research.

\section{El graffiti en el liceo: un abordaje hermenéutico y narrativo}

"En escuchar lo que nos dice algo y en dejar que se nos diga, reside la exigencia más elevada que se propone al ser humano" (Hans-Georg Gadamer, La misión de la filosofía, 1983).

El presente artículo narra brevemente el resultado de la investigación llevada a cabo con el objeto de lograr un primer acercamiento al fenómeno del graffiti en las instituciones liceales.

Los graffitis forman parte del escenario habitual de los liceos, se encuentran en salones de clase, corredores, escaleras, paredes, bancos, puertas, baños... y en cierta forma se han 
"naturalizado"; los docentes pasamos frente a ellos sin "mirarlos" ni "escucharlos". Sin embargo, constituyen una de las formas de expresión más genuinas de los adolescentes: nacen de ellos mismos, sin que sean dirigidos desde el mundo adulto.

El propósito general de esta investigación ha sido identificar y analizar los significados que los docentes y los estudiantes atribuyen al graffiti en el liceo. Se vuelven importantes ambas posiciones, la de emisor/escritor y la de receptor/lector, pues brindan pistas para la comprensión del fenómeno del graffiti, del estudiantado y de la tarea docente.

Dentro del sistema educativo, y específicamente en los liceos, conviven diversos actores: estudiantes, profesores, adscriptos, directores, bibliotecarios, administrativos, auxiliares de servicio etc. Pueden diferir, y a veces coincidir, en cuanto a su edad, función, formación, experiencia, perspectivas sobre el instituto, puntos de vista acerca de lo que es la educación, concepción del mundo, intereses, etc. No obstante, pese a sus diferencias, todos forman parte de esa institución en particular, en determinado momento de la historia. En este estudio se ha adoptado un enfoque hermenéutico, tomando principalmente los aportes del filósofo alemán Hans-Georg Gadamer (2006, 2007); y narrativo, en el cual el psicólogo Jerome Bruner (1997, 1998) ha desempeñado un rol central. Desde este enfoque las personas son tanto "escritores" como "lectores" de su propia vida. Su existencia puede ser interpretada como un relato, un texto donde van alternando los papeles de autor e intérprete.

Lo mismo sucede con la vida en el liceo: dentro de la institución se construyen relatos e interpretaciones sobre lo que sucede cotidianamente. Y el graffiti está ahí, haciéndose presente. No obstante, muchas veces se lo rechaza, olvida o ignora, como si se hubiera fusionado con el paisaje habitual. Pero el graffiti sigue estando ahí y representa la "cara oculta" de la educación, algo que subyace como sombra de la luz resplandeciente. "La 'cara oculta' de la educación en la vida cotidiana, su noche múltiple, solamente puede alcanzarse de reojo, a través de un múltiple trabajo interdisciplinar que combina la antropología, la sociología, la literatura y la filosofía. [...] El pensamiento pedagógico, como la mayor parte de la filosofía occidental, no puede con la 'sombra', con lo 'oscuro' y lo 'misterioso'. El conocimiento no es solamente 'diurno' sino también 'nocturno'. ¿Cómo se puede alcanzar el misterio?" (Mèlich, 1998, p.13).

Es importante recordar que: "No hay mundo sin palabras. Pero las palabras no equivalen a los conceptos. Las palabras también son íconos, imágenes, metáforas [...]" (Mèlich, 1998, pp. 27-28). El graffiti "habla", constituye la voz en bruto de los estudiantes, por eso también se puede "escuchar". "En rigor, no se puede enseñar nada sin haber escuchado previamente [...]. Y no sólo eso: hay que saber quiénes son nuestros alumnos, qué necesitan, adónde se dirigen, qué les gusta, qué es lo que es importante para ellos; cómo, en definitiva, se sitúan ante el mundo y qué funciones y roles van a desempeñar en él los años venideros. Hay que escucharles, ya que si no lo hiciéramos difícilmente podríamos acertar en qué les hemos de decir y en cómo hemos de transmitírselo" (Fabra y Domènech, 2001, 18).

Tradicionalmente se ha atribuido al docente el rol de narrador, considerando que el relato constituye la materia prima de la enseñanza, por la cual el trabajo docente cobra sentido. ¿Cómo narrar sin haber escuchado previamente? En este sentido resulta iluminadora, desde un ámbito literario, la siguiente frase del escritor uruguayo Eduardo Galeano (1940-): "El arte de narrar se aprende escuchando, siempre: eso no ha cambiado. Para no ser mudo hay que empezar por no ser sordo. Si vos no sabés escuchar no vas a saber hablar o en todo caso lo que digas no va a tener interés para los demás porque los laberintos de tu propio ombligo pueden ser apasionantes para vos pero para el resto de la humanidad no tienen porqué ser un tema que interese demasiado. Entonces creo que para poder hablar hay que saber escuchar y hay que recibir esas voces y aprender que las voces que valen la pena escuchar suenan, a veces, en los lugares menos presentables. Digamos, no en los foros universitarios, 
en los centros donde se reúnen los expertos para explicar cómo es el mundo, sino en lugares sencillos, simples, por ejemplo las paredes" (Entrevista realizada al escritor por Zarranz et al., 26 de diciembre de 2008).

\section{¿Qué se entiende por graffiti en el marco de esta investigación?}

"La palabra es un acto de dos caras. Está tan determinada por quien la emite como por aquel para quien es emitida" (Bajtín, Teoría y estética de la novela, 1989)

La palabra graffiti ${ }^{2}$ es relativamente moderna, pues recién aparece en diccionarios y enciclopedias durante el siglo XIX. Designa toda inscripción o representación gráfica (textos, dibujos, símbolos, signos, siglas, etc.) que se produce de forma espontánea y predominantemente anónima sobre cualquier superficie de un lugar público no concebida para tal fin. Constituye un medio de expresión no institucional, transgresor y ligado fuertemente al espacio urbano.

Suele distinguirse entre dos tipos de graffitis: el graffiti de palabras o de leyenda, que se destaca por el uso mayoritario del componente verbal, utilizando mensajes ingeniosos, directos, cortos e impactantes; y el graffiti de imagen, pictórico o mural, que da gran importancia a la forma y a la elaboración artística.

El graffiti presenta ciertas características que lo distinguen y definen: anonimato, clandestinidad, transitoriedad, espontaneidad, carácter dialógico y empleo de ciertos recursos característicos (síntesis, ironía, hipérbole, etc.). Estos aspectos son abordados con gran detalle en la tesis de maestría.

\section{La metodología y las técnicas de recolección de datos empleadas}

"Un texto está formado por escrituras múltiples, procedentes de varias culturas y que unas con otras establecen un diálogo, una parodia, una contestación, pero existe un lugar en el que se recoge toda esa multiplicidad y ese lugar no es el autor sino el lector" (Barthes, El susurro del lenguaje, 1984).

La presente investigación se ha basado en la perspectiva cualitativa. Esta metodología fue elegida porque permite comprender casos concretos en su contexto temporal y local, adecuándose perfectamente al tema y problema de este estudio. Asimismo, constituye un estudio de carácter exploratorio, pues se trata de uno de los primeros acercamientos al fenómeno del graffiti en las instituciones educativas, es decir, vinculado a la educación.

A su vez, corresponde a un enfoque biográfico-narrativo. Se ha buscado "dar la voz" al graffiti y escucharlo, para construir una narración a partir de los relatos de los principales actores involucrados (docentes y alumnos) en torno al graffiti dentro de la institución liceal.

El estudio se ha realizado en tres liceos de bachillerato $\left(2^{\circ}\right.$ ciclo de enseñanza secundaria) ubicados en Montevideo, capital de Uruguay (designados aquí como LA, LB y LC). También se ha realizado observación y relevamiento del espacio en un liceo más (LD), para brindar mayor riqueza a la investigación.

Las técnicas utilizadas fueron las siguientes: registro fotográfico, entrevista en profundidad a alumnos y docentes, grupos de discusión o grupos focales, e historia de vida de algunos de los graffitis más significativos, a partir de los relatos de los propios docentes y estudiantes. La fotografía ha constituido un instrumento central en esta investigación, ya que se ha realizado 
un cuidadoso y detallado relevamiento fotográfico. El empleo de fotografías como estrategia metodológica en el ámbito de la investigación educativa es relativamente reciente, razón por la cual ha sido ampliamente justificado a lo largo de la tesis, al igual que las demás técnicas utilizadas.

En una primera instancia, se ha efectuado un análisis paradigmático del material fotográfico, clasificando los graffitis de acuerdo a los siguientes criterios: ubicación (liceo en el que se encontró el graffiti), soporte material (lugar dentro de la institución en que se encuentra), formato (forma de expresión: dibujo, texto clásico, etc.), y elemento de producción (recurso con el que se ha elaborado, como ser aerosol, tiza, corrector, tallado, lapicera, etc.).

Posteriormente, la información empírica obtenida de las fotografías, las entrevistas y los grupos focales fue analizada cualitativamente. Se hizo necesario recurrir al método comparativo de los datos obtenidos en los liceos estudiados y, a partir de la identificación de cuestiones recurrentes, se hizo posible elaborar un conjunto de categorías interpretativas. Estas categorías no fueron construidas a priori, sino que surgieron de la interrelación entre teoría y empiria. Entre otras cosas, han permitido "ordenar" los graffitis por su temática o contenido, establecer su función y destinatario, identificar los móviles que llevan a graffitear en los liceos, y las visiones que tienen del graffiti los estudiantes y los profesores, lo que no habría sido posible previamente.

Este artículo se centrará en la presentación de las categorías interpretativas que emergieron de la propia investigación en interjuego con la teoría: "el tren", "el juego", "la firma", "la red social", "el grito", "la fobia”, "lo político", "fuera de actas", "el deporte”, y "el hostigamiento".

\section{Las categorías interpretativas}

\section{El tren}

"Lo más importante es, pues, aprobar, no aprender. Y menos aún, ser mejores personas. De ahi muchos vicios que se hallan presentes en las instituciones escolares"

(Santos Guerra, 2005).

Un "tren" o "trencito"3 es un papel pequeño con anotaciones o fórmulas que el estudiante lleva oculto, para copiar disimuladamente en los escritos o exámenes.

En todos los liceos relevados se ha encontrado una gran cantidad de graffitis cuya función es servir de estrategia para copiar en los escritos o, en otras palabras, ser usados a modo de "trencitos". Los hay de diversas asignaturas, y en ellos el destinatario es su propio autor, que le asigna a la inscripción una función utilitaria. En este tipo de inscripciones se encuentran reiteradas faltas de ortografía (marcadas con cursiva en la transcripción).

Los elementos de producción de este tipo de graffitis son, en la mayoría de los casos, lápiz de escribir o lapicera, y, con menor frecuencia, fibra de trazo fino. Permiten realizar la letra en un tamaño muy pequeño y en espacios reducidos, mientras que pasan fácilmente desapercibidos para el profesor. 


\section{Fotografía 1}

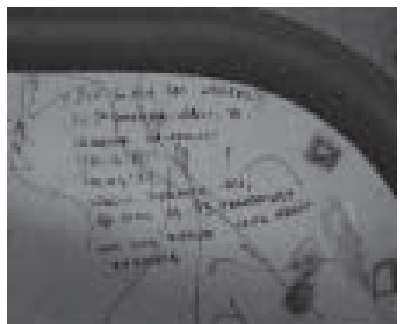

LA, salón 2 , banco de estudiante
"Fin siglo XIX paz armada. 14 primera guerra hasta 18. $10.000,60.000$. 117 R. R. Crisis 29. Stalin Fascismo, Vaz. G. Civil '39-'73, franquismo. Com. S XX Freud, cine masivo, tv Europa" (Tren de historia)

\section{Fotografía 2}

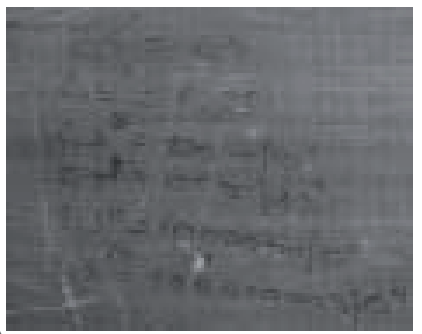

LB, salón 5, p. lat. der, madera
" $2,51=2,5$

$2,52=6,25$

$2,55=100 \rightarrow 102$

$2,510=10000 \rightarrow 104$

$2,515=1000000 \rightarrow 106$

$2,520=100000000 \rightarrow 108$ "

(Tren de matemática)

Si bien el lugar más común para estos graffitis es el banco del propio estudiante, como se acaba de ver, también se pueden hallar en los lugares más inverosímiles (estanterías, puertas, y cubiertas de tubos de luz).

\section{Fotografía 3}

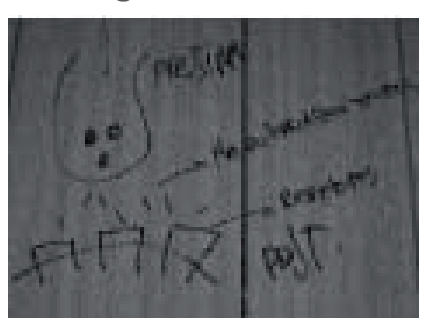

LD, salón creado en el pasillo, puerta

\section{Fotografía 4}

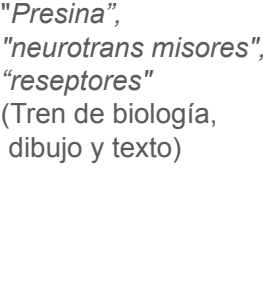

"neurotrans misores", "reseptores" (Tren de biología, dibujo y texto)

El relevamiento fotográfico ha mostrado que se emplea fibra común, gruesa, para realizar este tipo de inscripciones en lugares estratégicos, como ser la parte trasera de la cubierta de los tubos de luz ubicados en el techo del salón de clase. El lugar elegido pasa completamente inadvertido para el profesor, ya que desde su escritorio sólo ve el frente de la cubierta de la luz, que no tiene nada escrito. Y si fuera hasta el fondo del salón, tendría que levantar demasiado la cabeza para ver el "tren", ya que el techo es bastante alto. La fibra gruesa permite a los estudiantes escribir en caracteres grandes para que pueda ser vista desde el fondo del aula.

La enorme cantidad de graffitis empleados para copiar hallados en el correr de esta investigación, en los lugares más recónditos de las cuatro instituciones estudiadas, lleva a reflexionar acerca de algunas interrogantes relacionadas con la evaluación. ¿Por qué los estudiantes hacen inscripciones en forma de "tren" para copiar?, ¿qué sentido atribuyen al saber? Por otro lado, ¿qué es lo que se intenta evaluar?, ¿tiene relevancia en la vida de los estudiantes?, ¿las propuestas de evaluación se limitan a la reproducción de conocimientos o también a su producción? Y finalmente: ¿qué es importante y valioso enseñar? Todas estas preguntas hacen ineludible el planteo del problema de la evaluación (Litwin, Díaz Barriga, Santos Guerra, Jackson).

La Dra. en Educación Edith Litwin, quien ha investigado profundamente el problema de la evaluación, señala que ésta ha ido ganando terreno en el campo de la didáctica, pero como resultado de una "patología". Considera que el aspecto "central" de la evaluación es generar información para el docente acerca de su propuesta de enseñanza, siendo un aspecto "periférico" la que provee respecto a los aprendizajes de los estudiantes. No obstante, se 
ha producido una "patología", ya que muchas prácticas docentes se fueron estructurando en función de la evaluación: el profesor enseña lo que va a evaluar, y los estudiantes aprenden porque el tema enseñado forma parte fundamental de las evaluaciones. Es decir, "[...] en las prácticas de enseñanza, la actitud evaluadora invierte el interés de conocer por el interés por aprobar en tanto se estudia para aprobar y no para aprender" (Litwin, 1998, 12). La evaluación se ha convertido en el eje de las actividades docentes, produciéndose una inversión entre lo central y lo periférico antes mencionado. Se puede relacionar la noción de "patología" en la evaluación, de la que habla Litwin, con la distinción que realiza Miguel Ángel Santos Guerra entre "valor de uso" y "valor de cambio" en relación al conocimiento académico 4 .

Como resultado de la transformación del interés por saber en interés por aprobar, "el aula se transforma en un escenario de lucha entre el alumno y el docente por la calificación ("A ver si saco un punto más". "A ver si lo engaño" -piensa el alumno-. "No me voy a dejar pasar", "Ustedes son unos vagos", "Es la única forma que tengo de que trabajen" -piensa el docente.)" (Díaz Barriga, 1995, p.137). Es decir, sintéticamente, desde el punto de vista del docente, el estudiante pretende aprobar el curso haciendo el mínimo esfuerzo. Entonces, la evaluación pasa a ser una forma de que el alumno estudie y se involucre con la materia. Por otro lado, desde el punto de vista del alumno, en el liceo a veces le enseñan cosas que no tiene sentido aprender verdaderamente, ni le van a "servir" en el futuro. Entonces puede llegar a considerar la copia como una estrategia legítima para conseguir su objetivo: aprobar.

En la entrevista a una alumna, ésta contestó lo siguiente cuando se le preguntó si alguna vez había realizado alguna inscripción en el liceo: "No, yo que sé, alguna boludez así, chiquita... sí, como cualquiera [...] pero, yo qué sé, alguna fórmula de física" (Al. $\left.1^{5}\right)$. Es decir, el copiar es considerado desde los estudiantes como algo menor y, además, se sabe que muchos lo hacen.

Para los estudiantes y la mayoría de los padres, la institución educativa es importante porque permite avanzar y conseguir un empleo decente, frente a la situación actual signada por el desempleo y el trabajo mal remunerado. Sin embargo, como señala Charlot, no es el saber lo que interesa; se estudia para pasar de año porque el saber en sí parece haber perdido sentido.

En su libro "La vida en las aulas", Philip Jackson trabaja esta cuestión de la trampa, y afirma que la institución educativa es un lugar donde el estudiante aprende a cumplir un horario, a seguir ciertas rutinas, a realizar las actividades que se le asignen, a esperar, a renunciar a sus deseos, a vivir en el interior de una "masa", a dejarse evaluar por otros (el profesor, los compañeros), a recibir elogios y reproches, a guardar silencio, y a controlar sus movimientos. En otras palabras, aprende "el oficio de alumno". Sin embargo, muchas veces experimenta un conflicto que surge entre sus intereses y deseos, y las expectativas institucionales, por lo que desarrolla estrategias para abordarlo. Una de ellas es el engaño. "[...] Copiar una respuesta en un examen, fingir interés durante un debate, proporcionar una contestación falsa a una indagación del profesor y enmascarar actividades prohibidas son todo la misma cosa. Cada una representa un esfuerzo por sustraerse a la censura o por obtener un elogio inmerecido. Tales esfuerzos son más corrientes en el aula de lo que nos haría creer nuestra concentración en la copia durante los exámenes. Aprender a desenvolverse en la escuela supone, en parte, aprender a falsificar nuestra conducta" (Jackson, 2001, pp.66-67). Es decir, para el autor se trata de un "falseamiento" que se puede dar en cualquier aspecto de la vida escolar, y no sólo al copiar directamente en una evaluación. Sin embargo, se suele destacar sólo este último, mientras los demás pasan, o se dejan pasar, desapercibidos.

De manera que la cuestión de los "trencitos" da cuenta de un problema complejo y multidimensional, principalmente en el plano de la evaluación y la relación con el saber, en donde se entrecruzan las perspectivas de los docentes, de los estudiantes, y de la propia institución escolar. 


\section{El juego}

"Es juego la pura realización del movimiento" (Gadamer, Verdad y método I, 2005).

En algunos casos, la realización de graffitis en el liceo puede comprenderse como un juego. Es lo que sucede, por ejemplo, con las "conversaciones" que se establecen entre autores y lectores de graffitis, que escriben, leen y contestan, formando verdaderos diálogos, por pura diversión.

¿Qué se entiende por juego? El historiador holandés Johan Huizinga (1872-1945) estudió el juego como fenómeno cultural en su libro Homo ludens, que constituye todo un clásico en el tema. Allí sostiene que las imágenes convencionales del "homo sapiens" y el "homo faber" son insuficientes, y por eso propone la de "homo ludens", el hombre que juega, junto a las dos anteriores. El juego es una función humana tan esencial como la reflexión y el trabajo y, además, la cultura posee un carácter lúdico. El autor define el juego de la siguiente manera: "[...] el juego, en su aspecto formal, es una acción libre ejecutada 'como si' y sentida como situada fuera de la vida corriente, pero que, a pesar de todo, puede absorber por completo al jugador, sin que haya en ella ningún interés material ni se obtenga en ella provecho alguno, que se ejecuta dentro de un determinado tiempo y un determinado espacio, que se desarrolla en un orden sometido a reglas y que da origen a asociaciones que propenden a rodearse de misterio o a disfrazarse para destacarse del mundo habitual" (Huizinga, 1990, p.26).

De la conceptualización del autor se desprenden las características fundamentales del juego.

- Es una actividad libre, es decir, se lleva a cabo por placer y puede suspenderse en cualquier momento.

- Se diferencia de la vida cotidiana, ya que implica un escape de ésta hacia una esfera temporaria. El jugador hace "como si", esto significa que se entrega al juego, practicándolo con total seriedad, y cancelando momentáneamente el conocimiento de que es "pura broma".

- Está encerrado en sí mismo, es decir, se juega dentro de ciertos límites de tiempo y espacio. En relación al tiempo, el juego comienza y en determinado momento acaba. Con respecto al espacio, al jugar éste se "recorta": puede dibujarse (como se hace con la rayuela), desplegarse sobre la mesa (como ocurre con el tablero de ajedrez), o simplemente imaginarse. El liceo, entonces, se convierte en el tablero, el campo de juego para el graffiti. Pero, a su vez, dentro del liceo se escogen ciertos lugares, para lo cual es necesario "conocer el terreno", distinguir las zonas de riesgo, detectar los centros de fuerza y las zonas privilegiadas.

- Crea y exige orden, de forma que cada juego tiene sus propias reglas, que determinan qué es lo que vale dentro de ese "mundo provisional". Mientras se juega, el espacio y tiempo del juego se convierte en "el" mundo, mientras que lo demás deja de existir. El mundo de la vida liceal queda cancelado temporalmente mientras se "juega" al graffiti.

- Constituye un riesgo para el jugador. El riesgo, la tensión, la adrenalina que genera el juego, es lo que "hechiza" al jugador.

- Puede ser repetido en cualquier ocasión, pues una vez que ha sido jugado permanece en el recuerdo como posibilidad.

De las características anteriormente analizadas puede extraerse lo esencial del juego: el movimiento. El juego debe ser comprendido como un proceso de movimiento que se apodera de los jugadores. "El sujeto del juego no son los jugadores, sino que a través de ellos el juego simplemente accede a su manifestación" (Gadamer, 2005, p.145). Los jugadores sencillamente se "abandonan" al juego, realizan una "suspensión" de sí mismos para dejarse llevar por un movimiento que despliega su propia dinámica. Es decir, el juego se pone en marcha cuando 
los participantes lo toman con toda su seriedad. Este movimiento de vaivén, de oscilación, es vital para el juego, siendo indiferente quién o qué lo genera. Se trata de un movimiento muy cercano al de la naturaleza.

La Doctora en Filosofía y Letras Graciela Scheines (1998) distingue dos momentos sucesivos que se dan en el juego: la instauración del caos o el vacío, pues para empezar a jugar se hace preciso cancelar temporariamente el Orden del Mundo; y la fundación de un nuevo orden, el orden lúdico.

A efectos de esta investigación se podrían extrapolar estos dos momentos al "juego" del graffiti que se lleva a cabo cotidianamente en los liceos. Por un lado la instauración del caos se da al "interrumpir" el orden de la vida escolar: sus límites, normas, valores y jerarquías. Por ejemplo, la regla de mantener el local liceal en buen estado, claramente no es respetada cuando se rayan los bancos, paredes y puertas. Asimismo, la desarticulación del orden escolar se puede apreciar en los graffitis que cuestionan abiertamente la propia institución educativa. Por otro lado, la fundación de un nuevo orden se ve en el establecimiento de una nueva ortografía, el libre planteo de temáticas que no corresponden al currículum oficial, y la instauración de un nuevo espacio de poder, donde el anonimato sirve como garante para la efectuación del graffiti, y las paredes actúan como "imprentas" no oficiales.

El graffiti en sí -por sus características y su indeterminación-, constituye un "juguete" abierto, una fuente inagotable llena de posibilidades lúdicas.

A continuación pueden apreciarse algunas fotografías que ejemplifican "el juego". La "conversación", a través de contestaciones, agregados y tachaduras, es representativa de este tipo de graffitis, que tienen como móvil principal el humor y la búsqueda de diversión entre pares.

\section{Fotografía 5}

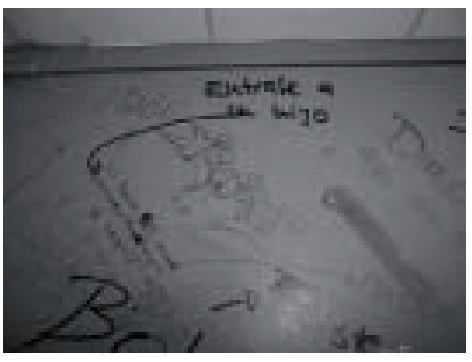

LA, baño alumnas, puerta
- "El tiene 28, una esposa, y tres hijos, q' hago? [Fue escrito por arriba]: El tiene 48 , unas esposas, y trece hijos, q' hago??

- ¿Sabi?

- Dejálo ya, pobre de su esposa y sus hijas!, y vos te vas a hacer mierda si seguís con él.

- Matate!

- Entrale a un hijo

- Te entiendo, pero a la larga o

a la corta te vas a hacer daño.

Besos".

\section{Fotografía 6}

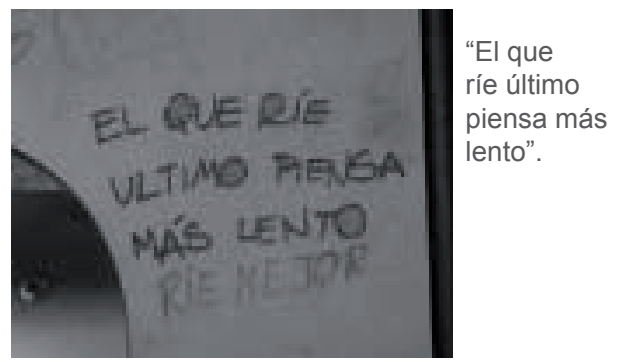

LA, salón $\mathrm{s} / \mathrm{n}^{\circ}$, banco estudiante

\section{"Ríe mejor"}

Los alumnos se refieren a este "juego" durante las entrevistas: "O de un profesor, me acuerdo que una vez puse: ¡i¡Qué bueno que está el profesor!!!”, de... no sé de qué era, física creo, de tercero...."Qué bueno que está el profesor!!!”, y alguien me comentó: ¡ii“Síííííííí!!!" [risas]” (Al.6).

En el primer grupo focal los estudiantes también hacen mención al juego:

- "(Alumna 18") En muchos son charlas. Una habla de una cosa, y la otra le da un consejo.

- (Alumna 14) En el baño pasa, en el baño se dan pila de consejos de cosas y todo... 
- (Alumna 2) ¡Ay!, no te sirven para nada...

- (Alumna 15) Dice: "amo al profesor de filosofía".

- (Alumna 2) También escriben groserías igual.

- (Alumno) Escriben groserías también...

- (Alumna 8) Pero te divertís...

- (Alumna 2) Vas leyendo y vas viendo...

- (Alumna14) O chistes también hacen.

- (Investigadora) Chistes también hacen, ¿es para divertirse eso?

- (Alumna) Sí, Claro.

- (Alumna 2) Están aburridos y rayan" (G.F.1).

El empleo de ciertos recursos como la ironía, la burla, la hipérbole y el lenguaje directo, a veces insultante, son propios de este tipo de inscripciones. Otros ejemplos de graffitis que implican un juego son los siguientes:

\section{Fotografía 7}

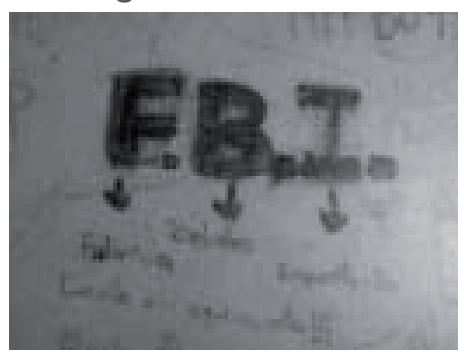

LA, salón $\mathrm{s} / \mathrm{n}^{\circ}$, banco estudiante
"F.B.I.: Fabrica Boludos Importantes"

\section{La firma}

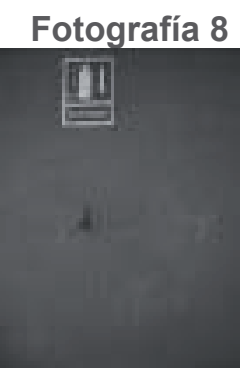

LA, pared pasillo
Extintor dibujado en el lugar donde un cartel indica que éste debería estar.

En los liceos abundan los graffitis a manera de firma, que consisten en escribir el nombre propio, un apodo, o un seudónimo. Generalmente la inscripción directa y legible del nombre es realizada en el propio banco del estudiante.

\section{Fotografía 9}

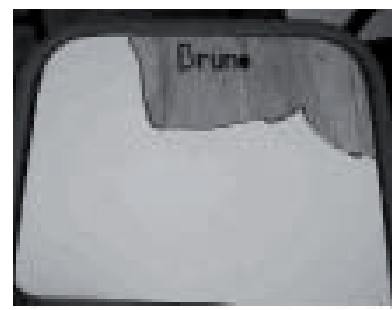

LA, salón 11, banco estudiante
Fotografía 10

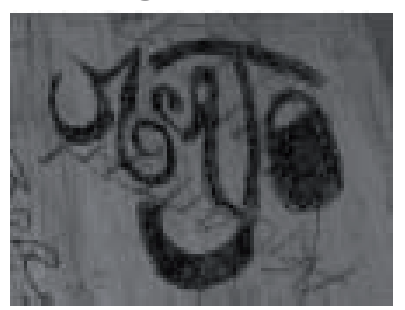

LC, salón 1 , mesa estudiante

Asimismo, en los liceos se han encontrado varios "tags" o firmas realizadas por los integrantes de la tribu urbana de los hip-hoperos. Cada firma es única; generalmente incluye iniciales, símbolos, asteriscos, flechas o números e implica un trabajo sobre la forma. En este sentido la investigadora argentina Lelia Gándara sostiene que la firma "[...] presenta un carácter intermedio entre lo pictórico y la escritura" (Gándara, 2002, 71). 
Fotografía 11

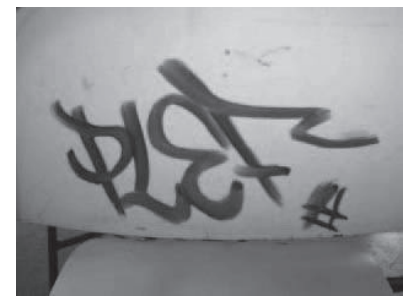

LA, salón 24, banco estudiante
Fotografía 12

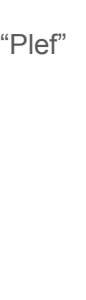

LA, escaleras
Fotografía 13

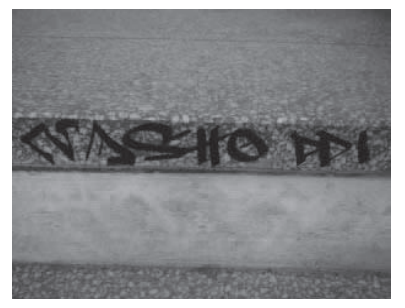

"Nasho
PPI"

http://www.montanacolors.com/productos. php?idf=1

En ellas el escritor o "writer" de hip hop, como se llama a sí mismo, encubre su identidad deformando la escritura y enlazando las letras, a fin de que su firma sólo pueda ser reconocida por el grupo al que pertenece. "Para los demás eventuales lectores será sólo una marca extraña que se reitera en diversos puntos del espacio urbano" (Gándara, 2002, 61). No obstante, a pesar de este "enmascaramiento" del que han hablado varios autores, se pone de manifiesto un fuerte deseo de exhibirse, de mostrarse, de darse a conocer. Se trata de lo que se podría denominar un doble juego de ocultamiento-exhibición.

Durante el segundo grupo focal los estudiantes mostraron su intriga en relación a estos graffitis "encriptados" y su elemento de producción: "Mirás y decís: ¡pa!, ¿qué será?, ¿qué significará?, porque todo tiene un significado" (Al. 2, G.F.2), "a mí me llaman la atención estos graffitis que he visto por todos lados, un montón de graffitis, que son de... Unos que dicen 'Epilef', otros que dicen 'Rev'[...] Y no son... y no son hechos con aerosol. Porque vos mirás y están hechos como con una especie de pincel" (Al.3, G.F.2).

El elemento de producción utilizado para la realización de los "tags" mostrados en las fotografías anteriores es el "marcador" ("marker") que utilizan los graffiteros hip-hoperos, como puede apreciarse por el tipo de trazo. Pero también pueden realizarse con aerosol, elemento de producción por excelencia de los hip-hoperos (ver fotografía 14), o fibra común (dry pen). Por otro lado, algunos tags han sido hallados en stickers.

Fotografía 14

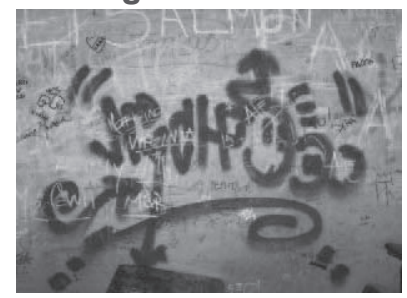

LD, salón 17, p. lat. der.

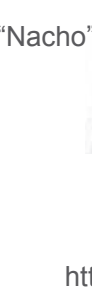

http://www.montanacolors.com/ productos. php?idf=1
Fotografía 15

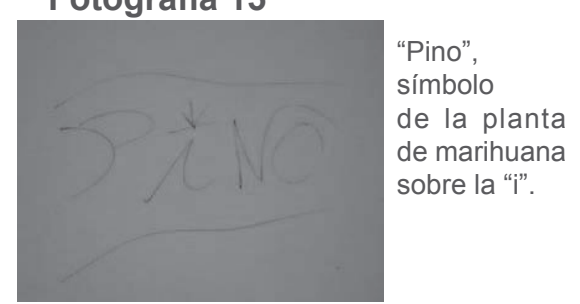

LA, pared, planta baja

Puede decirse que la inscripción de la firma (sea tag o no) cumple dos funciones que están muy imbricadas entre sí: dejar una huella de la propia existencia, y "marcar" el territorio. En relación al primer punto, la firma permite dejar para la posteridad una huella de la propia existencia, del propio pasaje por el liceo y la historia. La persona busca salir del anonimato. En cuanto al segundo punto, la firma permite marcar el territorio y apropiarse de él. Sin embargo, la noción de territorio no puede restringirse a un lugar geográfico y físico, pues también es un espacio simbólico, psicológico y existencial construido. "Marcar" o "trazar" el territorio significa delimitar lo propio y lo ajeno, el adentro y el afuera, el orden y el caos, lo familiar y lo desconocido. 
El graffiti con la firma va dirigido a su propio autor, en cuanto le inscribe su nombre y los dibujos que lo identifican, construyendo "su" territorio, y cargándolo de significado afectivo y existencial. Pero también va dirigido a sus propios pares, haciéndoles saber que ese lugar es "suyo", que de alguna forma le "pertenece", aunque de hecho no sea así. Entonces también marca un límite para los demás.

Es importante destacar que la realización de la firma encubierta o "tag" no se limita al banco propio, como puede apreciarse en las fotografías. Sus soportes son muy variados, desde bancos y ventanas hasta puertas, lámparas y paredes. En este tipo de graffitis las dos funciones mencionadas están muy presentes, sumadas a una fuerte necesidad de exhibición. Pero da la sensación de que hay algo más detrás: "Porque no es una hoja que después tiro; además no lo hago en un lugar escondido, lo hago en un lugar que se vea, o sea...Es un llamado de atención" (Prof.2).

\section{Fotografía 16}

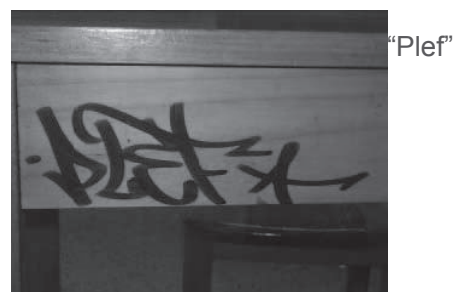

LA, salón 24, escritorio prof.
Fotografía 17

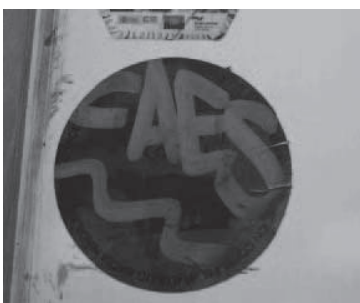

LA, salón 2, pizarrón
Fotografía 18
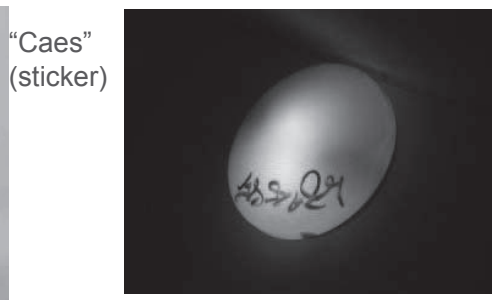

LA, lámpara, escaleras

En la fotografía 16 puede verse un "tag" en el escritorio del profesor. Aquí podría hablarse de una provocación, un quiebre de los límites en un grado mayor. Pero se trata de quebrar los límites, no a través de un cuestionamiento, sino escribiendo el propio nombre o alias identificatorio. Esto hace pensar que los destinatarios del graffiti son más los propios pares que las autoridades, es como si le dijera a su propio grupo: "miren hasta dónde puedo llegar". Esto le otorga "fama" y lo posiciona en un lugar destacado dentro de su grupo. "También puede haber algo de, ¿cómo se dice?, de violación de la norma que queda impune, y que también a veces alimenta nuestro ego, o el ego del supuesto violador, supongo yo, ¿no? Es hacer una... hacer algo que se sabe que está prohibido, pero que no tiene consecuencias, yo qué sé" (Prof.3).

Por último, en los liceos también fue encontrado un tipo particular de graffiti, que es realizado quemando con fuego las paredes y techos de los liceos.

Fotografía 19

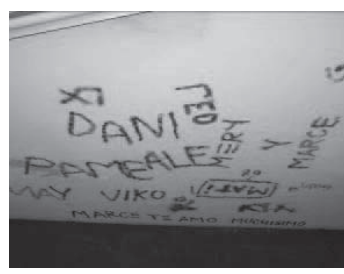

LB, salón Arq., techo
Fotografía 20

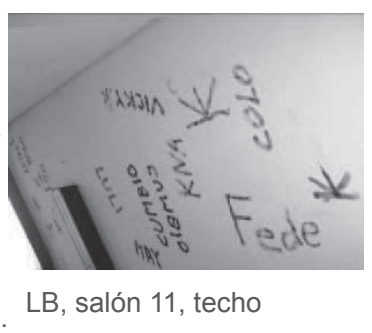

Fotografía 21

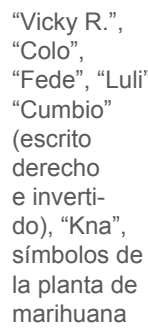

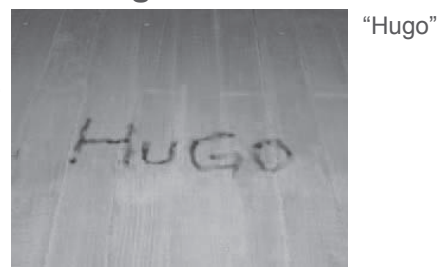

LD, salón 13 , techo 
Este graffiti cumple varias funciones: exhibición, autoafirmación, impresión de una huella de la propia existencia y marcación del territorio. Los estudiantes lo atribuyen a los "planchas"6, de forma que también mostraría la pertenencia e identificación con una tribu urbana (las tribus urbanas y el graffiti han sido estudiados en el marco de esta investigación, y puede encontrarse mayor información en la tesis final). Generalmente en este tipo de graffitis es anotado el propio nombre, o el propio y el de la pareja.

Uno de los profesores entrevistados cuenta el siguiente relato, que tal vez se podría hacer extensivo a estas inscripciones, de grandes proporciones, realizadas con fuego en los techos y paredes de las instituciones: "Un acto vandálico, es decir, un acto de destrucción que no tiene aparente sentido, y ahí también, yo supongo también, puedo esperar una especie de resentimiento. Cuando fue robada una escuela y después le prendieron fuego... una escuela pública todavía, o un merendero, ¿sí? Y le prenden fuego, o lo queman, o lo destruyen gratuitamente... ¡qué fuerte! ¡Qué energía mal canalizada!, mal... brutal. Pero allí no puede haber otra cosa que el resentimiento, la frustración y la marginación" (Prof.3).

\section{La red social}

"Yo no sé dónde véis y donde está la diversión de enseñar a todos tu careta de la exhibición", "Quiero estar en todos lados, en todos lados, papá. Poner mi foto en grande, mi estado de ánimo. Quiero estar en todos lados, en todos lados, mamá".

(Tote King, disco "Redes Sociales", 2010).

El registro fotográfico en las cuatro instituciones liceales mencionadas ha permitido recoger la existencia de un graffiti propio del siglo XXI. Se trata de un graffiti donde se escribe la dirección del Fotolog, el Metroflog, el Blog, el correo electrónico o la dirección de Facebook. El mismo puede hallarse en diversos lugares de las instituciones: salones de clase, baños, pasillos, patio; y en varios soportes: bancos, paredes y piso. Su destinatario son los propios pares, y su función es clara: establecer una comunicación o un vínculo social con los pares en el mundo virtual. Durante las entrevistas y los grupos focales puede verse que los alumnos están muy habituados a este tipo de inscripciones. En esto se diferencian de los profesores, pues ninguno conocía la existencia de este tipo de graffitis. Esto puede explicarse por dos razones: en primer lugar, las redes sociales virtuales constituyen un fenómeno muy reciente; y en segundo lugar, se trata de inscripciones dirigidas a los pares.

La palabra "fotolog" deriva de la inglesa photoblog, que podría traducirse como "bitácora fotográfica". En un "fotolog" el elemento central es la fotografía. Generalmente se publica una por día, y está acompañada por los comentarios de su autor. La mayoría de los usuarios aceptan comentarios, en forma de "libro de visitas", que habitualmente se refieren a la fotografía o a los hechos relatados. Además, en el fotolog hay enlaces a los fotologs de los amigos, lo que lo convierte en una red social.

En los liceos estudiados los sitios más utilizados para la creación de fotologs son:

www.fotolog.com y www.metroflog.com. Los adolescentes, cuando escriben la dirección en el liceo, muchas veces abrevian anotando la palabra "flog" o "mf", o dos barras, y luego su dirección. Participan en estas redes para que "los vean", "los conozcan", y "ser populares". 
Fotografía 22

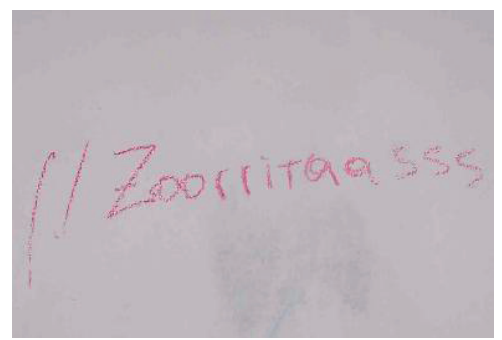

LB, salón 13, p. frente

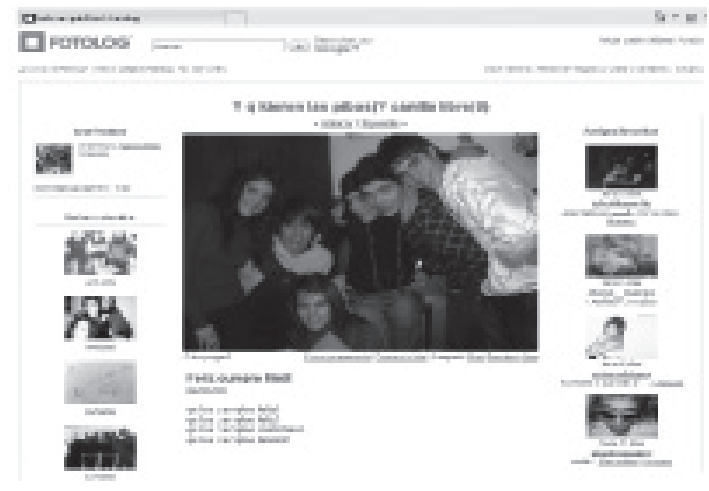

www.fotolog.com/zoorritaasss
Fotografía 23

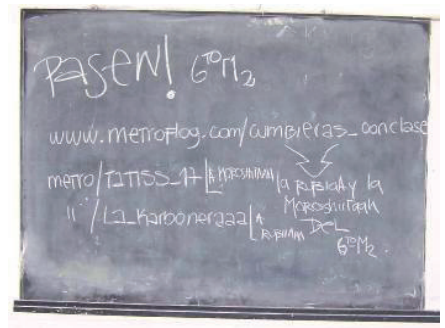

LD, salón 2, pizarrón

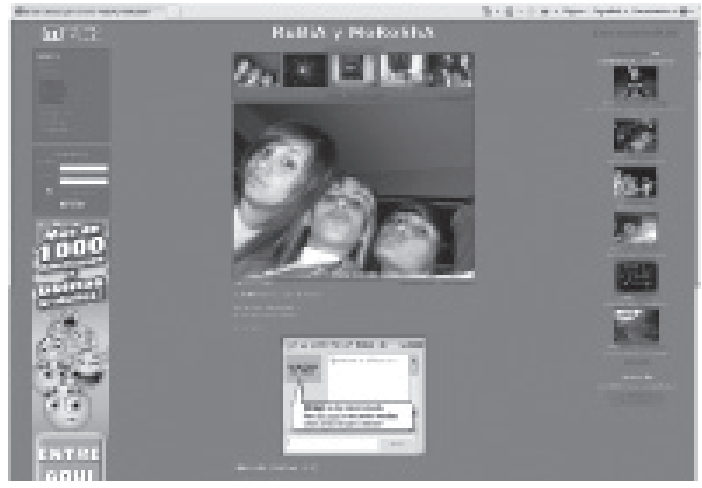

www.metroflog.com/cumbieras_conclase

Los estudiantes atribuyen la elección del sitio para crear el fotolog a la tribu urbana a la que se pertenezca. Así, los floggers utilizarían fotolog, y los planchas metroflog: "Vos si mirás está bien estructurado: los floggers usan fotolog, los planchas usan metroflog" (Al.3, G.F.2).

Este tipo de inscripciones comenzó a realizarse en los liceos de nuestro país en el año 2008, período en que se comenzó a hacer masivo el uso de fotolog, con la interfaz en español y el surgimiento de nuevos sitios desde donde crearlos. Coincidió con el período en que comenzó el relevamiento fotográfico en los liceos mencionados (2008-2010).

Desde mediados del año 2009 comenzó a ganar terreno en nuestro país Facebook, un sitio web de redes sociales, gratuito, creado por Mark Zuckerberg. Una alumna explicaba esto de la siguiente manera: "a veces escuchabas decir, 'vos sos no sé qué', porque claro, se reconocían por el fotolog, no por el nombre...No, sí, a veces escuchaba. Tipo, ta, ahora está más tranqui la cosa, quedó medio en un segundo plano el Fotolog, ahora está el Facebook" (Al.8).

La mayoría de los alumnos dice tener Facebook. Le ven como ventaja "el hecho de que encontrás gente, tipo, metés el nombre de alguien y de cualquier lado y yo me encontré con pila de gente tipo amigos y eso que están en el exterior... pila" (Al.8).

En el primer grupo focal los estudiantes dialogaban de la siguiente manera en torno a Facebook:

- "(Alumna)" Soy adicta a Facebook.

- (Alumna 16) Todos...

- (Investigadora) ¿Facebook sí tiene la mayoría?

- (Varios alumnos) Sí.

- (Alumna 16) Yo dejo Facebook en mi computadora todo el día, capaz me voy, pero está ahí" (G.F.1). 


\section{Fotografía 24}

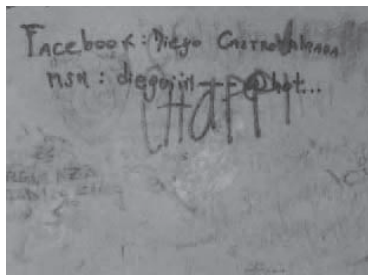

LD, salón 14 , banco al.
Fotografía 25

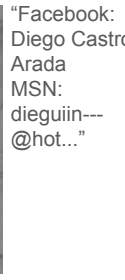

LC, patio, baldosa.
Fotografía 26
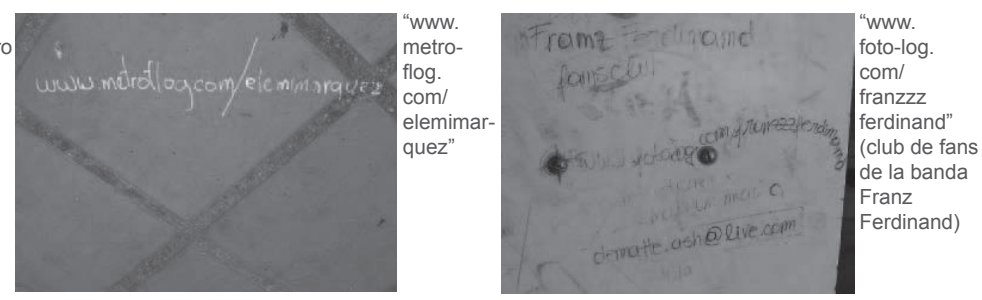

LA, salón 21, banco al.

Como ha analizado el crítico Zygmunt Bauman, existe cierta "carrera" por tener un perfil personal en la red social más reciente y de "más onda", porque el no tenerlo supone una "muerte social". Podría decirse que se está ante una nueva forma de entender la dinámica privadopúblico. Ya no se trata, como en la modernidad, de dos ámbitos bien diferenciados. Ahora la mayoría de las personas (no es una cuestión meramente generacional de adolescentes) buscan hacer público lo privado, hacerse visibles, y exponer su "yo interior" en la red. En cierta forma se muestran a sí mismos como "productos" deseables de adquirir, algo típico de la "sociedad de consumidores" actual: "Ellos son, simultáneamente, los promotores del producto y el producto que promueven" (Bauman, 2008, 17).

Pese a que prácticamente todos los estudiantes indican tener un perfil en alguna red social, un alumno sostiene que no tiene Facebook, y manifiesta una actitud más crítica ante la exposición pública: "no sé, es demasiado, yo por ahí soy un poco reservado, pero no me parece bien andar publicando a todo el mundo mi... me parece un poco más personal... Y no he entrado [a direcciones de fotolog y demás, escritas en el liceo]" (Al.9).

\section{El grito}

"Caminaba yo con dos amigos por la carretera, entonces se puso el sol; de repente, el cielo se volvió rojo como la sangre. Me detuve, me apoyé en la valla, indeciblemente cansado. Lenguas de fuego y sangre se extendían sobre el fiordo negro azulado. Mis amigos siguieron caminando, mientras yo me quedaba atrás temblando de miedo, y sentí el grito enorme, infinito, de la naturaleza" (Edvard Munch, 1893, El grito).

En las instituciones educativas relevadas se han encontrado graffitis que traducen un grito; un grito de angustia y de ira, un grito que hace retumbar las paredes. Esta pintura lo plasma con toda su fuerza expresiva, deteniendo el tiempo en un perpetuo

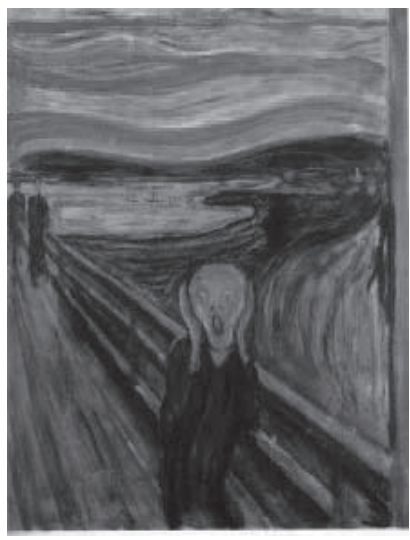
dolor.

\subsection{El grito de dolor}

El grito de dolor y angustia tiene como caso paradigmático en Latinoamérica el de la escuela secundaria de Carmen de Patagones, al sur de la provincia de Buenos Aires, en la que un alumno disparó a sus compañeros de clase (2004). En la fachada de la institución se encontraron, en ese período, algunos murales que causan desasosiego: hombres armados con máscaras, figuras fantasmagóricas, y en el pupitre del autor de la masacre se encontraron algunas inscripciones inquietantes. Estos graffitis, ¿podrían haber sido una señal o un mensaje de lo que finalmente iba a suceder?, ¿qué acciones pudieron haberse tomado frente a los mismos? La tragedia 
ocurrida en Carmen de Patagones conduce a la reflexión, desde el dolor, sobre este tipo de expresión de los estudiantes. Claramente son inscripciones e imágenes que traducen un grito, un sufrimiento. Tal vez un grito mudo, pero grito al fin, que se deja oír en las paredes.

Algunos de los graffitis encontrados en el marco de esta investigación que traducen un gran sufrimiento, son los siguientes. Dan cuenta de un pedido y una necesidad de ayuda, una necesidad de ser escuchado.

\section{Fotografía 27}

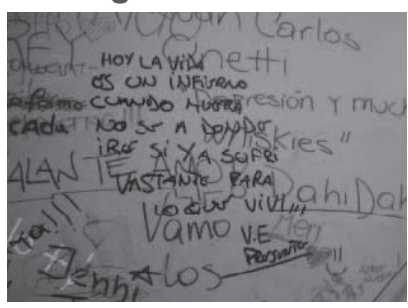

LA, baño alumnas

\section{Fotografía 28}

"Hoy la vida es un infierno. Cuando muera no sé a donde iré si ya sufrí vastante para lo que viví. V.E. Prosonia"

El grito de dolor muchas veces es expresión de estudiantes víctimas del hostigamiento por parte de otros alumnos, que los insultan y agreden, también a través de las paredes.

\subsection{El grito de rabia}

El grito de rabia e ira implica un cuestionamiento y una crítica a las instituciones educativas. La fuente o el móvil que lleva a su realización suele ser una necesidad de catarsis, de liberación.

\subsubsection{Escuelas en Ilamas}

Los graffitis mostrados en las fotografías 29-30 y sus variantes, siempre mantienen las mismas características. Presentan grandes dimensiones, ocupando aproximadamente la mitad de la pared. Este tamaño de letra excesivamente grande para un espacio reducido como es el salón de clase sugiere un grito. Además, el elemento de producción es crayola roja. Este color es asociado inmediatamente al fuego, que sumado al mensaje "Escuelas en Ilamas", traduce la idea de incendio. Coincidentemente es el color del que hablaba Munch en su descripción de "El grito".

\section{Fotografía 29}

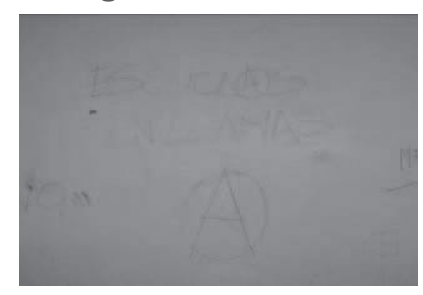

LB, salón 17, p. lat. izq.

\section{Fotografía 30}

"Escuelas en llamas", símbolo de anarquía.

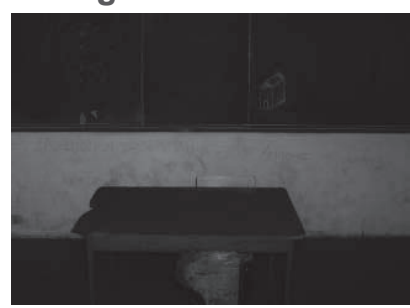

LB, salón 17, p. frente
"La lección de hoy: poner entre barrotes tu cerebro". 
Detrás de estas inscripciones se esconde la ideología anarquista, como se manifiesta en el uso de su símbolo, la letra "A" rodeada por un círculo. Estudiantes y profesores asocian estos graffitis con sentimientos como el rencor, la rabia y la angustia (nótese la similitud de los mismos con los que expresa un grito). Igualmente, ambos recalcan que no saben si hay un verdadero conocimiento de fondo de la ideología anarquista que reivindica el autor de la inscripción, ni si se trata simplemente de una "moda", es decir, de algo que se sigue en forma temporal, pero no definitivamente.

Una estudiante interpreta estos graffitis de la siguiente forma: "Para mí es como que las instituciones tienen normas, reglas y pautas de comportamiento, y cosas que hay que seguir, supongo que es eso a lo que quieren llegar, quieren quemar las normas de las instituciones...Y que ya están quemadas en realidad, ¿no?, que nadie las respeta, y por eso 'Escuelas en llamas'"(Al.6). O como plantea más enfáticamente: "Que la norma se quema, que la norma...a ver...ya está, que está muerta. Que tiene que morir" (Al.6). Muchos de los alumnos entrevistados se refieren a las normas y reglas de la institución educativa como algo que molesta cumplir. Pero esta cita trae a colación un tema esencial: la crisis de la escuela (esta cuestión de la crisis de la escuela en tres áreas: fundamento, identidad y palabra, es desarrollada con mayor profundidad en la tesis). ¿En qué sentido la institución liceal está "quemada", incendio que quiere hacer patente este graffiti? La misma alumna explica: "Estas cosas no se deberían hacer, y se hacen [mira hacia las inscripciones en bancos y paredes que hay en el salón de clase donde llevamos a cabo la entrevista]. Ahora, por ejemplo, el respeto hacia el profesor se ha perdido, digo, lo digo desde adentro, ¿eh? [...] Como que ya uno salta y ya eso es perder el respeto, ¿no?, digo, antes tenías que tener un tono hacia el profesor, mismo el profesor ya no te respeta a esta altura de la vida, es como que le pedís una explicación y dice: 'Y yo lo quiero así', eso ya es perderse en cierta forma" (Al.6).

\subsubsection{Liberación animal}

Otro tipo de graffiti que expresa un grito dentro de la institución liceal es el que dice: "Liberación animal", que fue encontrado tanto en el Liceo A como en el Liceo B. Este graffiti, por un lado, hace referencia al veganismo; $y$, por otro, manifiesta una fuerte crítica al sistema.

Fotografía 31

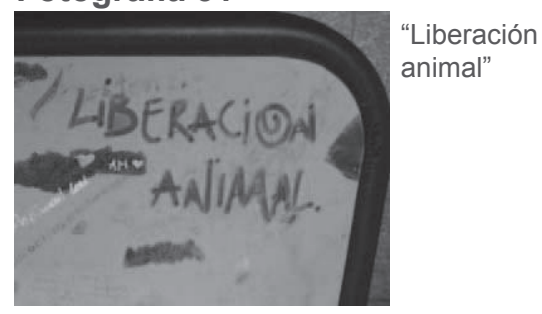

LA, salón com., banco estudiante

\section{Fotografía 32}

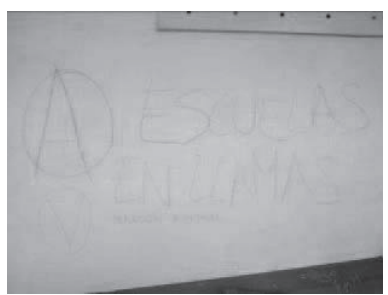

Graffiti 1: "A", símbolo

de anarquía, y

"Escuelas en llamas"

Graffiti 2: "V",

posiblemente símbolo

de veganismo, y

"Liberación animal"

En relación al primer punto, el vocablo "vegano" es un préstamo lingüístico de la palabra inglesa "vegan" que, a su vez, surgió como contracción del adjetivo "vegetarian". De manera que los veganos son los vegetarianos que, además de no comer ningún tipo de carne, tampoco incluyen en su dieta productos derivados de los animales, como ser huevos, productos lácteos o miel. Sus representantes no utilizan animales para su vestimenta o calzado, ni asisten a espectáculos donde los maltraten. El veganismo rechaza cualquier forma de explotación de los animales (zoológicos, circos, frigoríficos, experimentación, etc.), y se opone al especismo. 
En cuanto al segundo aspecto, este graffiti cumple una clara función de denuncia y crítica al sistema. Uno de los alumnos entrevistados señala: "es un graffiti, para mí es medio denuncia, o sea, es un graffiti denunciando. Eso no era tan artístico, era más un reclamo mío que no tenía que... capaz que es un poco obligar a gente a que te escuche, ¿no?" (Al.2). Aquí se hace patente la necesidad de ser escuchado, de plantear una visión distinta a la dominante, en un país dedicado a la producción ganadera, que registra una de las mayores cifras de consumo de carne en el mundo.

Los estudiantes realizan una segunda interpretación de estos graffitis, entendiendo "liberación animal" como una protesta, como la búsqueda de liberación del "animal humano", que sería el estudiante que se siente "reprimido" dentro del liceo. "Me parece que lo que expresan es un poco la represión que sienten en una institución educativa" (Al.4). Nuevamente se hace presente el tema de las normas de las instituciones educativas. En este sentido es importante señalar que dentro del veganismo existe un grupo denominado "anarco-punk" que, como su nombre lo dice, también son anarquistas y punks. Tal vez por eso se explique la realización de este graffiti, que parece haber sido hecho posteriormente y por otra persona, debajo del ya escrito "Escuelas en Ilamas", como si quisiera "fusionarse" con él.

\subsection{3. iProfesores!, idejen a los chicos en paz!}

En los liceos relevados se encontraron inscripciones en bancos de estudiantes haciendo referencia al álbum "The Wall” (1979), de la banda de rock británica "Pink Floyd”.

"Pink Floyd", y

dibujo de un muro
Fotografía 33

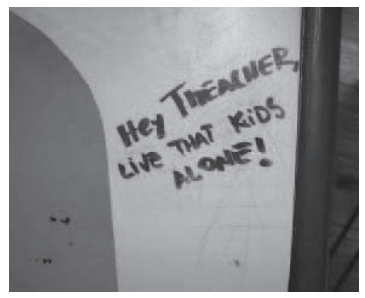

LA, salón 21 , banco estudiante
Fotografía 34

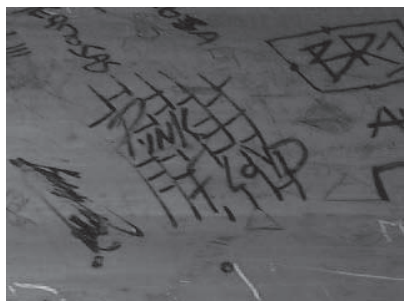

LC, salón Art, mesa estudiante
"Hey theacher,

ive that kids

alone!"

(¡Eh!, ¡profesor!, ¡deja a los

chicos en paz!)

Un alumno interpreta de la siguiente forma la realización de estos graffitis en el liceo: "capaz que fue por... dio alguna queja a la educación, y capaz que un poco de denuncia al lavado de cerebro que hacen los profesores, o capaz que fue una simple cosa, yo qué sé, cómica... Capaz que estaba en alguna clase de administración y contabilidad" (Al.2). El graffiti, entonces, puede haber sido hecho por rabia ante una materia que no interesa ni se le ve utilidad, pero también puede constituir una dura crítica al sistema educativo: "Más que los profesores... no tanto mirando al profesor, sino a la función que hacen, o sea, a la jerarquía. También muchas veces los profesores tienen que hacer así porque lo tienen que hacer así, porque es su trabajo, ¿entendés? Pero, me parece, la educación en sí manipula bastante la información que te dan, y creo que te dan muchas cosas que te sirven y que la gente las tiene que aprender; pero creo que también te dan muchas cosas que por ahí ayudan más a, no sé, es medio como que divulgan ciertos valores, cierto estilo de vida ¿no?, individualista, competitivo" (Al.2). Obsérvense los términos utilizados: "lavado de cerebro", enseñanza para ser "obediente", divulgación de una forma de vida "individualista" y "competitiva", "manipulación" de la información. 
En el primer grupo focal los estudiantes conversaron en torno al primer graffiti, al que ven como un "grito de liberación"; pero no en el sentido que tuvo originalmente, cuando fue escrito por Pink Floyd, sino como reacción ante un profesor que "molesta". O tal vez, explican, sólo lo haya escrito un fanático del grupo. En el grupo focal vuelve a surgir el tema de la crisis de la escuela; una crisis de la que son conscientes los estudiantes: "Ahora es al revés, [...] antes los profesores hacían lo que querían con los alumnos, les pegaban. Y ahora los alumnos hacen lo que quieren con los profesores" (Al.2, G.F.1). ¿Qué significa esto?, ¿el "castigo" pasó de un plato de la balanza al otro, de un extremo al otro?

\subsection{El grito en memoria}

Un tercer tipo de inscripciones que reflejan un grito son las que han sido escritas en recuerdo de alguien que falleció en forma violenta.

El viernes 8 de mayo de 2009 dos alumnos, Rodrigo N. y Rodrigo B., de 15 y 17 años respectivamente, fueron asesinados en las inmediaciones del Estadio Aguada, en el marco de un partido de básquetbol entre los cuadros Nacional y 25 de Agosto. El lunes 11 el liceo al que asistían cerró por duelo. El miércoles 13 se realizaron dos marchas en reclamo de justicia. Al frente de las marchas organizadas luego de los asesinatos iban chicos con fotos de las víctimas y un cartel con una frase que había escrito el estudiante R.B., apenas unos días atrás: "La tolerancia es ver a las personas como son, y no querer que sean iguales a vos". Esta frase parecía cuadrar misteriosamente con las circunstancias, dado que los asesinatos fueron consecuencia de la agresión y la intolerancia en el ámbito deportivo, entre hinchas de diferentes equipos.

Luego de los crímenes el liceo se cubrió de graffitis y esténciles haciendo referencia al hecho. La Dra. Claudia Kozak denomina graffitis "en memoria" a este tipo de inscripciones que recuerdan a alguien que ha fallecido, generalmente de forma violenta e inesperada.

Fotografía 35

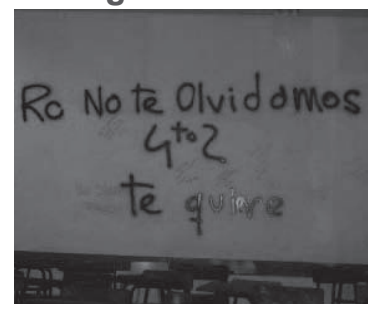

Salón 7, p. fondo

\section{Fotografía 36}

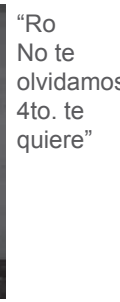

Entrada liceo, p. lat. izq.
Fotografía 37

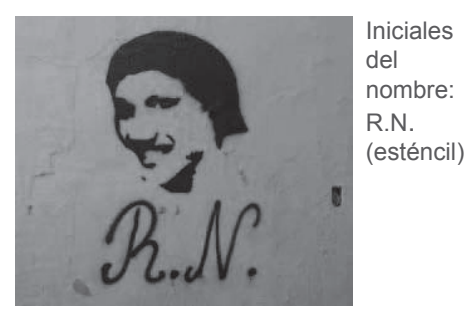

Entrada liceo, p. lat. der.

Los graffitis en memoria encontrados en el liceo presentan los siguientes rasgos:

- Se dirigen tanto a la persona muerta como a sus potenciales lectores.

- Muchas veces presentan la estructura de una "carta pública", ya que constan de un encabezamiento con el nombre de la persona fallecida, a quien se dirige explícitamente el mensaje; un cuerpo del texto con el mensaje y una firma.

- Aspiran a "construir un diálogo de fantasmas y tender un puente hacia ese otro construido textualmente, sí, pero considerado 'real'" (Kozak, 2004, p.157).

- Tienen grandes dimensiones. 
Fotografía 38

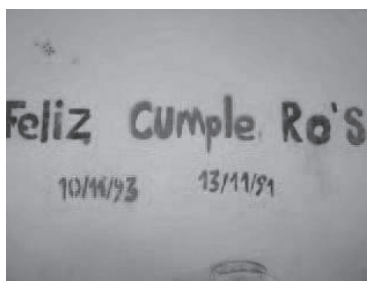

Pasillo
Fotografía 39

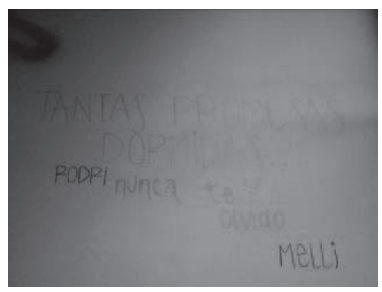

Salón 7 , p. fondo
Fotografía 40

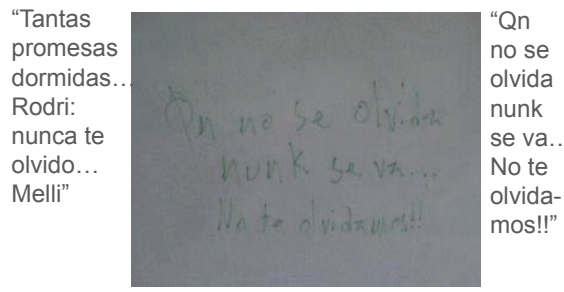

Salón 7,p. fondo

Las funciones que cumplen estos graffitis son las siguientes:

- Expresión de un sentimiento de dolor y angustia, desahogo, necesidad de ser "escuchado".

- Recuerdo de los alumnos asesinados para mantenerlos vivos en la memoria colectiva. "Por eso, quebrar la mirada indiferente que habita la gran ciudad es la política específica que puede atribuirse al graffiti [...]" (Kozak, 2004, p.163).

- Concientización acerca de la violencia por la que atraviesa la sociedad. "Un tipo de graffiti que, en definitiva, habla de una sociedad toda que convive con la muerte 'gratuita' propia de un estado de cosas cimentado por la marginación y la violencia generalizada" (Kozak, 2004, p.163).

- Protesta ante un hecho injusto y necesidad de subsanarlo.

Una estudiante analizó críticamente el crimen de los Rodrigos durante la entrevista, tratando de ir a las raíces del problema: la falta de educación en la sociedad en general, de la cual la falta de tolerancia sería sólo una consecuencia. No los considera modelos de vida, sino jóvenes que sufrieron las consecuencias de una sociedad en decadencia. "Son personas con muy poca educación, y que no se lo critico a ellos, sino al sistema educativo, ta, también a sus familias y los padres y todo eso, ¿no?, que son víctimas de lo mismo, me parece que pasa por ahí. 0 sea, ta, sabemos que la sociedad está pasando por un momento bastante bajo, ¿no?, y me parece que es fruto de eso, no tanto de que sean intolerantes, ¿no? Que sean intolerantes es una consecuencia más, ¿entendés?, de todo lo que son por la falta de educación que tienen. Y nada, cómo se tomó acá el tema de los Rodrigo no me pareció... no me pareció muy adecuado, ¿no?. [...] A ver cómo te explico, me pareció algo bastante... que se lo tomaron muy religiosamente, ¿no?, los pusieron en el lugar del mártir, ahí, hicieron marchas y cosas que me parecieron bastante fuera de lugar. [...] Ellos no son íconos de un liceo, ni modelos de vida, ni cosas como se empezaron a escribir por ahí, o sea, fueron dos chiquilines que, ta, sufrieron las consecuencias de una sociedad en decadencia, como le podría haber pasado a cualquiera, ¿no? Que no salvaron a nadie, no son ningún dios ni ningún santo, ¿no?” (Al.5).

\section{La fobia}

"El problema no es de raza ni de extranjería: es de pobreza. Por eso hay algunos racistas y xenófobos, pero aporófobos, casi todos" (Cortina, 2000, El País).

El corpus documental fruto de la presente investigación ha mostrado la existencia de algunos graffitis que manifiestan fobia y rechazo. 


\section{Fotografía 41}

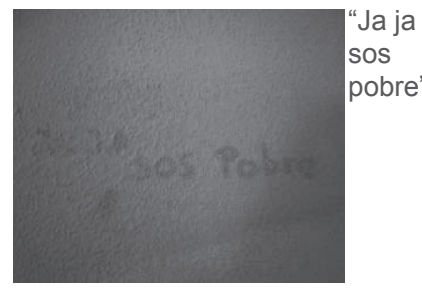

LA, pared, escaleras
Fotografía 42

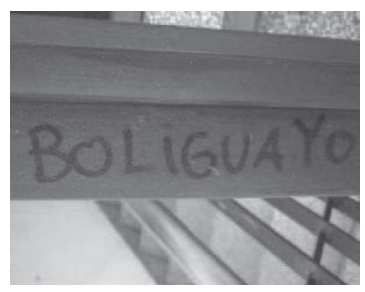

LA, varanda escaleras

\section{Fotografía 43}
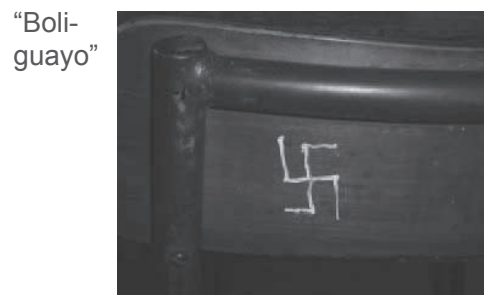

LB, salón 2, banco al.

Las dos primeras inscripciones representan casos de aporofobia, y la tercera de xenofobia. El término "aporofobia" ha sido forjado por la filósofa española Adela Cortina (2000), y profundizado por el también filósofo español Emilio Martínez (2002). Cortina define este concepto de la siguiente forma: "'Dícese -podría constar en la caracterización, por analogía con otras- del odio, repugnancia u hostilidad ante el pobre, el sin recursos, el desamparado'" (Cortina, "El País", 2000, 1).

La palabra "aporofobia", entonces, designa la repugnancia hacia el pobre, a la que hace referencia directa el primer graffiti. Este rechazo es alimentado por sentimientos de miedo ("los pobres son violentos o violentos en potencia"), o de asco ("son sucios o tienen pocas nociones de higiene"), que lo hacen crecer. Martínez sostiene que aquí está operando un mecanismo psicológico, pero no un razonamiento correcto. Se trata de la falacia de la generalización apresurada: se parte de algunos casos particulares ("este mendigo cometió tal acto de violencia", "tal persona siempre está sucia", etc.), y a partir de ellos se llega a una conclusión general de tipo universal: "todos los mendigos son peligrosos", o "todos los pordioseros son sucios". Estas generalizaciones apresuradas tienen el riesgo de conducir a otra más: los pobres son culpables de su situación (porque son sucios, violentos, haraganes, no educan a sus hijos, etc., etc.).

En cuanto al segundo graffiti, "boliguayo" sintetiza la unión de dos palabras: "boliviano" y "uruguayo". Este graffiti podría haberse considerado como un caso de xenofobia, que claramente también lo es. Sin embargo, se ha optado por tomarlo como un caso de aporofobia, siguiendo a Adela Cortina, cuando se refiere al rechazo al pobre de esta forma: "[...] es la fobia hacia el pobre la que lleva a rechazar a las personas, razas y etnias habitualmente sin recursos" (Cortina, "El País", 2000, 1). Es decir, plantea que la xenofobia es una consecuencia de la aporofobia, de la hostilidad hacia el que es pobre. Si hubiera "boliguayos" exitosos y ricos, probablemente no estaría escrito este apodo tan despectivo en las escaleras de un liceo.

En relación al tercer graffiti, la esvástica es una cruz cuyos brazos están doblados en ángulo recto, ya sea en sentido horario o antihorario. La palabra proviene del sánscrito swastika, que significa: "muy auspicioso", y se piensa que el símbolo fue creado en el siglo V a.C. Sin embargo, a comienzos del siglo XX el nazismo adoptó la cruz esvástica como emblema. El desarrollo del nacionalsocialismo y otras formas de totalitarismo, primero en Alemania y luego en gran parte de Europa occidental, -que afirmaba equivocadamente la superioridad de la "raza aria" en oposición a la "raza judía" o semita-, llevó a la persecución, deportación a campos de concentración y genocidio de judíos europeos. Es lo que se conoce como Holocausto.

Durante las entrevistas y grupos focales los estudiantes se refirieron espontáneamente a este graffiti, que se encontró en varios de los liceos relevados fotográficamente. "En un principio hubo gente que empezó a hacer, a rayar, así, con drypenes las paredes, así, como éstas, con comentarios antisemitas y comentarios también a la gente, no sé... "Maten a los planchas", o... 
“Judíos no sé cuanto"... con esvásticas, y... era un poco triste, ¿no?, pero... vergonzoso, ¿no?, triste y vergonzoso, porque no puede ser que en el 2010, casi 2010 , estamos entrando, y la gente se burle de la forma de pensar del otro" (Al.3). Una alumna comentaba: "[...] Se transformaron en un medio de comunicación medio negativo, las paredes, los bancos y todas esas cosas" (Al.1). Las paredes son presentadas directamente como un "medio de comunicación", un lugar para expresarse. Pero este medio de comunicación se estaba usando negativamente, como instrumento para el rechazo y la hostilidad. Luego de que apareciera esta esvástica, algunos estudiantes comenzaron a colgar carteles en el liceo donde decía: "Cuidá el liceo", y "Por el respeto a la diversidad no nos agredamos".

De acuerdo a lo señalado por los estudiantes, la realización de una esvástica puede representar la ideología nazi, o pensamiento antisemita, que es el motivo principal que señalaron todos. Pero también dan otras posibles interpretaciones, señalando que la esvástica puede corresponder a un símbolo de buena suerte, tomando el significado original del símbolo: "eso en realidad no tiene porqué ser nazi, digo, esa cruz en realidad porque la agarraron los nazis" (Al.3, G.F.2). O podría tratarse de una "rebelión" contra el sistema en sí: "Es una manera de expresarse contra el sistema, ¿no?. Es como hacer la A de anarca. Es una manera de decir: a mí no me importa que no me dejen, yo lo hago igual" (Al.3, G.F.2).

\section{Lo político}

"El problema no es que nos mientan, el problema es que les creamos" (Graffiti, Mayo francés, 1968)

Los graffitis agrupados bajo esta denominación responden a manifestaciones políticas de diversa índole. Fueron tratados en la tesis por haber sido encontrados en los liceos, pero no corresponden a lo que se entiende propiamente por graffiti en esta investigación: son inscripciones que no responden a ninguna institución.

\subsection{La expresión gremial}

En el interior del Liceo B se han encontrado cuatro graffitis murales o pictóricos, en los cuales el límite entre graffiti y arte parece borrarse. Fueron realizados por el gremio de estudiantes de esa institución durante una ocupación estudiantil, que se habría llevado cabo en ese liceo en el año 2002, de acuerdo a lo conversado con algunos docentes de la institución. Un profesor, que trabajaba en el liceo en ese momento, relataba: "Están vinculados con una ocupación, que no recuerdo cuándo fue... ¿sí? Pero antes de la ocupación no estaban y después de la ocupación aparecieron... Yo no estuve, en ese momento, pero me acuerdo que la policía sacó a los muchachos que estaban adentro... Que no hubo violencia excesiva, pero siempre hay algo de violencia... y... y recuerdo, tengo la idea que después de la ocupación aparecieron esos... esos muros pintados, ¿sí?" (Prof.3). Ninguno de los estudiantes tenía idea de cuándo habían sido realizados esos murales, ni en qué circunstancias.

Uno de los profesores entrevistados señalaba que estos murales le recordaban a los diseños gráficos de los discos de rock de los 70 a los 90, como "Genesis" y "Yes". "[...] Cuando los... te cruzás con ellos diariamente, ¿no?, y bueno, seguramente que hay muchos que les pasan por arriba... yo cada vez que los miro me recuerdan esa estética, ¿no? Es una estética un poco... expresionista, ¿sí?, de línea gruesa, de figura distorsionada, pero fuertemente expresiva, aparentemente cuestionadora, ¿no?, no es una pintura de paisajes alpino, sino que por el contrario pretende comprometer al espectador en una postura, eso es...'Tu silencio es 
complicidad'. Eso es un llamado a la movilización, digo, realmente me parecen muy... muy atractivos, y sobre todo muy... en un liceo público, que uno de repente piensa... en un liceo privado de repente no te lo dejarían pintar, ¿sí?" (Prof.3).

Fotografía 44

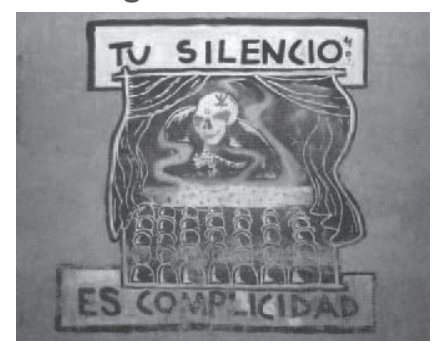

LB, pared del pasillo, planta baja

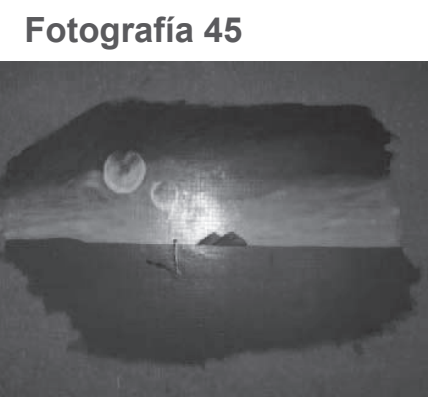

LB, pasillo, primer piso

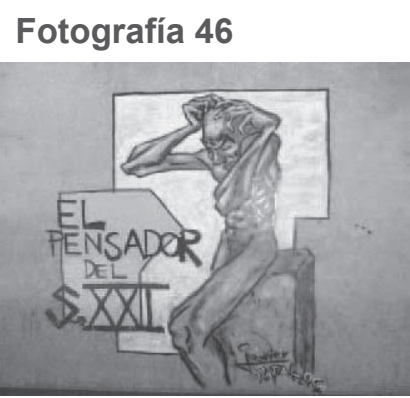

LB, pasillo, planta baja

En relación al primero de ellos, los alumnos señalaban: "Y bueno, ése para mí es un mensaje, como te había dicho, político, más desarrollado, ¿no?, que una 'A' de anarquía. Es como un mensaje una onda medio político, ta, si te parece que algo está mal, hablá, o sea, reaccioná, porque si te quedás callado, por más que no seas vos la causa de eso, de alguna manera sos cómplice. Entonces, me parece que ése es el mensaje, así lo entiendo yo" (Al.4).

A este mural se le han realizado "reincorporaciones" en forma posterior, como ser: el símbolo de la planta de marihuana sobre la frente de la calavera, el número 404 al lado de las palabras "tu silencio", y un sol en el centro de la frente, por encima de los ojos.

En relación al segundo graffiti pictórico, una estudiante indicaba: "ése es bastante surrealista, me parece que le podés encontrar las interpretaciones que quieras" (Al.5). Al mismo también se le han realizado "agregados": un papel rojo pegado a la altura del pubis, probablemente representando el órgano genital masculino del hombre que está de pie, y dos "cuernitos" de diablo sobre su cabeza.

En un tercer mural encontrado en el Liceo B aparece un hombre desnudo, tomando su cabeza con las manos, y la leyenda: "El pensador del siglo XXI". En este mural figura la firma de "Javier Pataloca". A un profesor le recuerda las obras del escultor suizo Alberto Giacometti (1901-1966) porque las figuras humanas que éste realiza son alargadas y torturadas, con fuerte componente de expresividad y surrealismo.

Estos graffitis murales surgieron de una acción gremial, en el contexto de una ocupación. Cumplen una clara función política, de denuncia y reclamo, y también de llamado a la movilización. Su destinatario es múltiple: estudiantes, autoridades (tanto del sistema educativo como político), y la sociedad en general.

\subsection{Año de elecciones nacionales}

Los años 2009 y 2010 han sido años electorales en Uruguay. En 2009 se eligió al Presidente de la República, y en 2010 a los Intendentes de los diferentes departamentos. Como todo fenómeno que ocurre en la sociedad, también la política permeó las instituciones liceales. Así lo demuestran algunos de los siguientes graffitis encontrados en el interior de los liceos. El apodo "Pepe" hace referencia a José Mujica (1935-), candidato a la presidencia por la coalición Frente Amplio, que finalmente fue electo Presidente de la República, en segunda vuelta, el 29 de noviembre 2009. El tercer graffiti hace mención al plebiscito por la Ley 15.848 de Caducidad 
de la Pretensión Punitiva del Estado, conocida como "Ley de Caducidad" que fue aprobada en Uruguay en 1986. Esta norma impide que los militares sean juzgados por violaciones a los DDHH cometidos durante la última dictadura militar (1973-1985). Este plebiscito no alcanzó la mayoría para que fuera anulada la ley, pues obtuvo el $48 \%$ y necesitaba la mitad más uno de los votos.

Fotografía 47

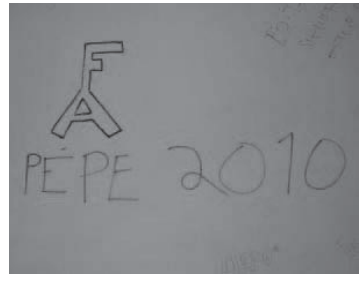

LB, salón 7, p. fondo
Fotografía 48

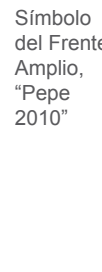

Símbolo
del Frente
Amplio,
"Pepe
2010"

LC, patio, pared
Fotografía 49

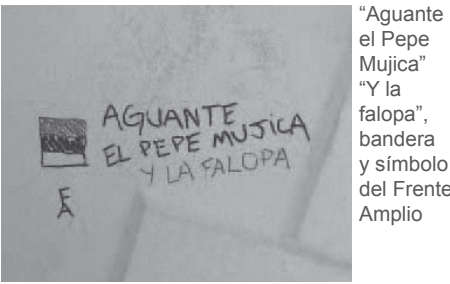

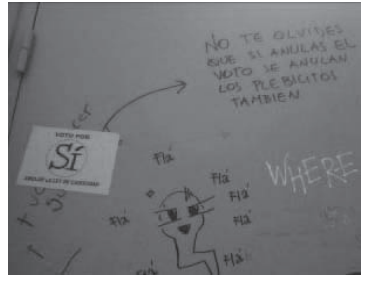

LA, baño alumnas

Un estudiante se refería a la política de la siguiente manera durante la entrevista: "Y las cosas que tienen atada a la gente en este mundo... deporte, fútbol y la política [se refiere a los temas que reconoce dentro de los graffitis en el liceo]. Y sí, los que nos tienen controlados, ¿no?, porque yo creo que más o menos es lo mismo ser hincha de un cuadro de fútbol que ser hincha de un partido político, porque la gente hoy en día está... mal de la cabeza... Mal, mal, mal... Porque está muy identificada, muy embanderada, pero lo que pasa que todo esto viene desde los cimientos de la persona" (Al.3). Esto lleva a pensar que la política a veces también puede convertirse en un "sentimiento religioso", en términos de Le Bon, cuando implica un fanatismo ciego a un líder o partido político.

\section{Fuera de actas}

"La solución consiste en legalizar" (graffiti, LA, banco de un alumno).

Estos graffitis, sobre el amor y el sexo, han sido agrupados bajo la denominación "fuera de actas" pues no corresponden a los temas del currículum escolar, es decir, se encuentran fuera de toda certificación, testimonio, asiento o constancia de un hecho.

\subsection{El amor y el sexo}

Los graffitis de contenido sexual o amoroso constituyen una de las temáticas más fácilmente identificadas por los estudiantes y los profesores en las entrevistas, junto a los graffitis deportivos y los de inscripción del nombre propio. Se han encontrado en gran número en los liceos relevados fotográficamente.

A continuación pueden observarse algunos graffitis de índole amorosa:

Fotografía 50

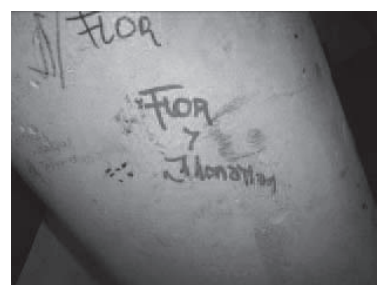

LB, salón 16, columna
Fotografía 51

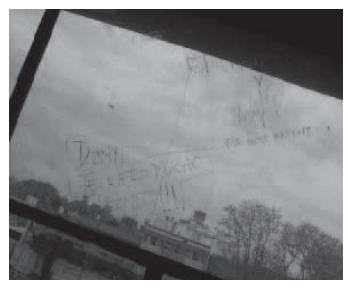

Liceo D, salón 13, ventana
Fotografía 52

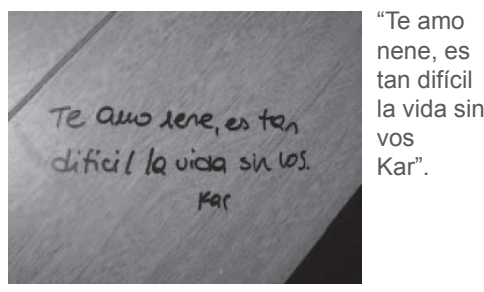

Liceo D, salón s/n, puerta 
Este tipo de graffitis se caracteriza por constar de un receptor en particular al que se transmite el mensaje. En algunas ocasiones hay poemas o frases de amor dedicados a ese destinatario especial, como en el caso de las fotografías precedentes. Estas inscripciones hacen público un sentimiento privado.

Estos graffitis de amorosos personales conviven con y/o se convierten en insulto, por ejemplo, para el novio/a con quien peleó el autor de los mismos. En esos casos, el "amor" se transforma en "venganza" o "revancha", que se manifiesta en las paredes, a través de agresiones.

En el interior de los liceos también se halló gran cantidad de graffitis con contenido sexual, como puede verse en las siguientes fotografías.

Fotografía 53

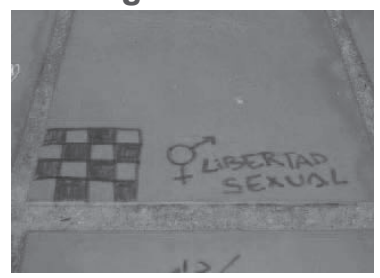

LC, patio, baldosa
Fotografía 54

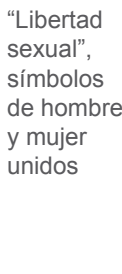

$$
\text { LC }
$$

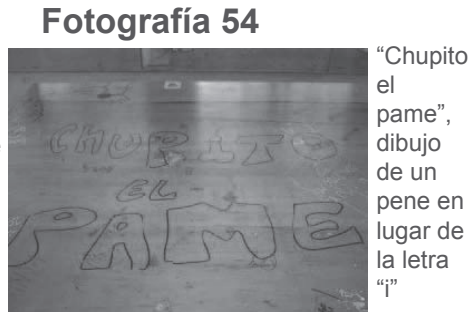

LC, salón 1, mesas al.

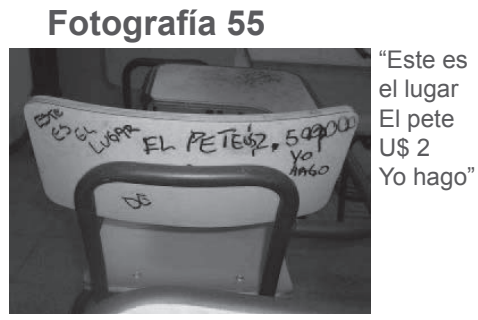

LA, salón biol., banco al.

Un profesor señalaba la existencia de estos graffitis: "Hay algunas cosas que tienen que ver con [...] lo sexual, ¿no? De repente es una ordinariez, de repente alguna cosa un poco más leve, pero...' 'Chupa tanto', 'Fulanito se la come', o 'Menganito no sé cuanto'. Bueno, ese tipo de cosas aparece y... que no es nuevo tampoco eso, ¿no?, eso existe hace mucho tiempo. Pero... también si uno mira la televisión de ahora y la de antes se da cuenta de que están expuestos a cosas así. Y el lenguaje mismo, a veces dicen cosas entre ellos que si se hubiese dicho en otra época y... yo... yo estoy bastante viejo, uno le hubiese clavado un piña. [...]. Les parece natural... porque en el ambiente se ha hecho natural lo vulgar parece" (Prof.2).

Estos graffitis representan los órganos genitales, especialmente el pene, refieren a la homosexualidad, la libertad sexual, el sexo oral, etc., generalmente con dibujos explícitos. Su destinatario es múltiple, y se busca exaltar la sexualidad, provocar, o divertirse entre pares.

\subsection{La droga}

En los liceos fue hallada una enorme cantidad de graffitis relativos a la droga. Entre ellos la marihuana es la más mencionada o dibujada:

\section{Fotografía 56}

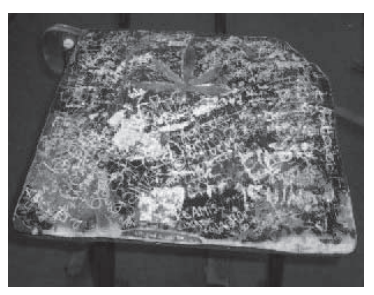

LB, salón 13, banco al.
Fotografía 57

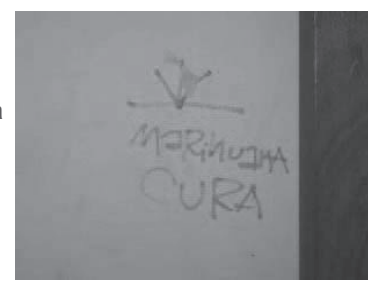

LA, salón s/nº, p. fondo
Fotografía 58

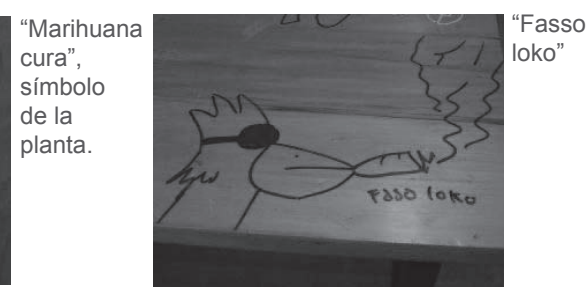

LC, salón 1, mesa al. 
Los profesores se refieren a la droga en el liceo. Uno de ellos señala que otros colegas le han comentado que a veces los estudiantes cruzan a la vereda de enfrente al liceo, y allí fuman marihuana, pero que la verdad preferiría no encontrar una situación así. "No, no sé, capaz que se van a fumar un porro... enfrente, para estar más lejos de la puerta. Pero no, no sé... Estoy fuera de actas... Claro, no sé, también eso de alejar... separa, pero no sé bien" (Prof.1). Otro de los docentes entrevistados señala que no es lo mismo encontrar a un alumno fumando solo, a primera hora de la mañana, que a varios fumando en grupo.

Además de la marihuana, en los liceos se han hallado graffitis haciendo referencia a otro tipo de drogas, como el LSD y los hongos, además de éter.

La función de este tipo de graffitis es promover el consumo de droga, o en algunos casos manifestar que sea legalizada. No tienen un destinatario específico, y se encuentran en diversos lugares del centro educativo, desde bancos, hasta el escritorio del profesor, paredes y pisos. Cuando se encuentran en estos últimos tres lugares, puede hablarse de una provocación más fuerte.

\section{Fotografía 59}

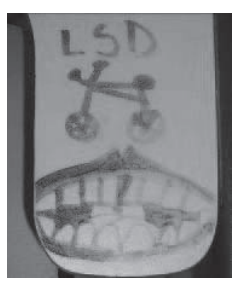

LA, salón 25, banco al.
Fotografía 60

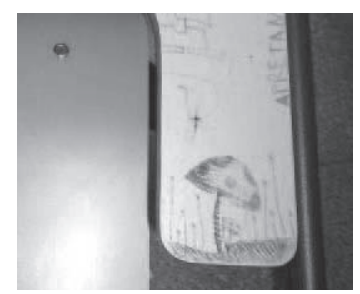

LA, salón s/nº banco al.
Fotografía 61

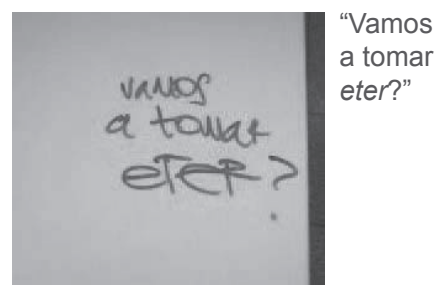

LA, salón s/nº escritorio prof.

\section{El deporte}

"Sos mi locura, sos mi alegría"

(Graffiti, LA, banco alumno)

En los liceos se ha detectado una gran cantidad de graffitis deportivos, principalmente de fútbol y básquetbol. A esto se suma que en el año 2010 se llevó adelante el campeonato Mundial de Fútbol, en el que Uruguay llegó al cuarto puesto, por lo que fueron hallados varios graffitis relativos al tema.

Fotografía 62

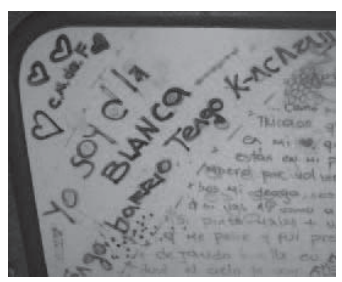

LA, salón s/nº banco al.
Fotografía 63

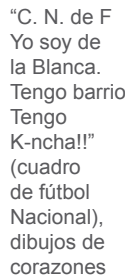

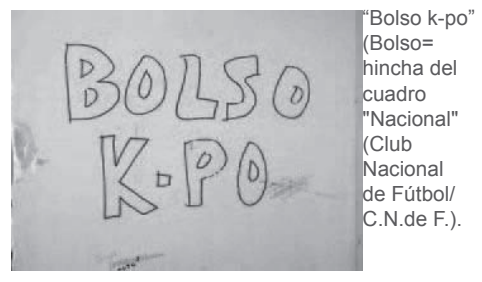

LB, salón $\mathrm{s} / \mathrm{n}^{\circ}$, p. lat. der.
Fotografía 64

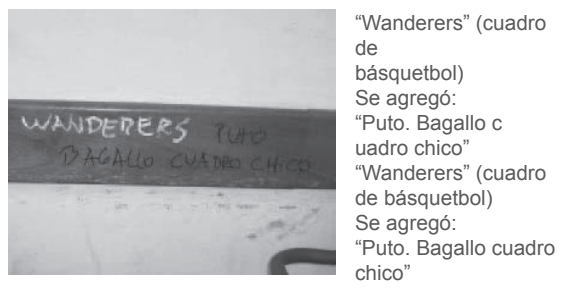

LC, salón 1, mesa al. 
En el graffiti deportivo se agrega, a la expresión de la identidad (a través del cuadro al que se pertenece, que tiene relación con el barrio en los cuadros de básquetbol), la rivalidad y la disputa por el espacio, en analogía con la rivalidad en el campo de juego.

Los adjetivos utilizados para describir al cuadro propio o criticar al ajeno se repiten de forma constante: "capo", "manda”, "aguanta”, "campeón"; o "puto”, “cagón”, "gallina”. Por otro lado, el nombre del cuadro aparece abreviado o bajo un seudónimo bien conocido por sus hinchas y contrincantes: "Peña" o "Manya" para Peñarol, "Trico" o "Bolso" para Nacional. También se abrevian los adjetivos, por ejemplo: "k-po" en vez de "capo".

Un estudiante señalaba: "Algunos agrediendo, 'Manya puto' [cuadro de fútbol Peñarol], 'Bolso capo' [cuadro de fútbol Nacional], o 'Bolso corré', 'Manya no sé qué'... Estupideces. Y... en realidad esos graffitis son lo mismo, sólo que cambia el sujeto, ¿viste?" (Al. 2). Además, son típicas de este tipo de inscripciones las tachaduras, las superposiciones, los agregados y las deformaciones del mensaje inicial. También se utilizan los recursos propios del graffiti, como el ingenio a través del juego de palabras (por ejemplo, la palabra "Penadoy", en lugar del nombre del cuadro "Peñarol").

\section{Fotografía 65}

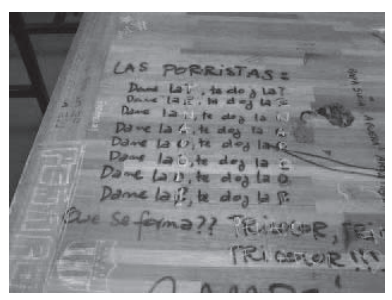

LC, salón 1, mesa al.
"Las porristas:

Dame la $\mathrm{N}$, te doy la $\mathrm{N}$

Dame A, te doy la A

Dame C, te doy la C

Dame I, te doy la I

Dame O, te doy la O

Dame $\mathrm{N}$, te doy la $\mathrm{N}$

Dame A, te doy la A

Dame L, te doy la $L$

Qué se forma??

Tricolor, tricolor, tricolor!!!" (A esas

letras se les escribió por arriba con corrector: "Peñarol")

\section{Fotografía 66}

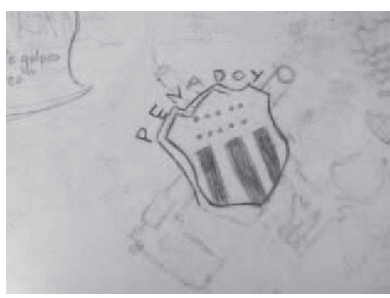

LA, salón 25 , banco al.

En este tipo de graffitis muchas veces está presente la referencia a la droga: el dibujo del símbolo de la planta de marihuana, la referencia al cuadro como "locura" y "alegría". Esto último es característico de los cantos de cancha de las hinchadas o "barras bravas", que también son transcriptos en diversos soportes dentro de los liceos. Incluso se han observado imágenes o palabras asociadas a la muerte del cuadro contrincante, como ser ataúdes y crucifijos.

¿Cómo puede explicarse la proliferación de tantos graffitis deportivos en los liceos, cargados de agresividad? Por supuesto que esto tiene que ver con las características de una sociedad en su conjunto, de la que las instituciones educativas forman parte.

Se intentará explicar este fenómeno de fanatismo deportivo a través de la noción de "sentimiento religioso" propio de las masas, propuesta por el escritor Gustave Le Bon (18411931). El sentimiento religioso, según este autor, presenta los siguientes rasgos: adoración de un ser al que se supone superior, temor al poder que se le atribuye, sumisión ciega a sus mandamientos, imposibilidad de discutir estos dogmas, deseo de difundir estos dogmas, y tendencia a considerar como enemigos a todos los que rechazan su adopción. 
Este sentimiento religioso puede manifestarse no sólo en relación a Dios, sino también a un ídolo, un héroe, una idea política, social, o un cuadro de fútbol. Le Bon toma el relato del novelista ruso Fiódor Dostoievski (1821-1881) acerca de un nihilista que, queriendo seguir las luces de la razón, rompió todas las imágenes de las divinidades y santos que adornaban el altar de su capilla, y apagó los cirios. Acto seguido, sustituyó esas imágenes por las obras de algunos filósofos ateos y volvió a encender los cirios. "El objeto de sus creencias religiosas se había transformado, pero, ¿puede afirmarse, en realidad, que habían cambiado sus sentimientos religiosos?" (Le Bon, 2000, p.61).

Guiadas por este sentimiento religioso, las masas dotan de poder a un ser que consideran superior -en el caso que nos compete, el cuadro de fútbol al que se pertenece-, convirtiéndolo en su meta y guía de sus sentimientos y acciones. A él lo siguen ciegamente, con todos los "ardores" del fanatismo. Todos los que no lo "veneran" están en el error, son "enemigos" que rechazan la verdad. Si a esto sumamos la gran violencia de la sociedad de hoy en día, se pueden explicar las grandes rivalidades, los continuos insultos y agresiones entre hinchas de distintos equipos deportivos que se manifiestan en los graffitis liceales, así como la "locura" que dicen sentir.

\section{El hostigamiento}

"El acoso escolar entre alumnos es una epidemia silenciosa" (Jorge Srabstein, 2006, La Nación).

Por hostigamiento o acoso escolar (bullying, en inglés) se entiende cualquier forma de maltrato físico, verbal o psicológico dentro de las instituciones educativas. Sin duda se trata de un fenómeno antiguo; sin embargo, su estudio sistemático comenzó en la década de los setenta.

En la actualidad es cada vez más corriente el hostigamiento a través de la utilización de la tecnología (redes sociales, mensajes de texto, etc.). Sin embargo, también existen otras formas de llevarlo a cabo, más clásicas, pero muy vigentes y poco estudiadas, como es el caso de los graffitis en las paredes de los liceos. A continuación pueden observarse algunos de ellos:

Fotografía 67

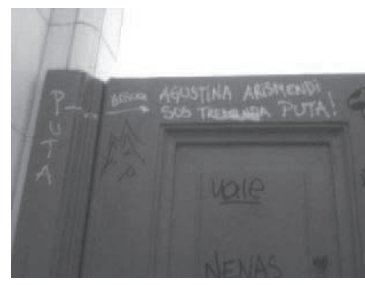

LA, baño alumnas
Fotografía 68
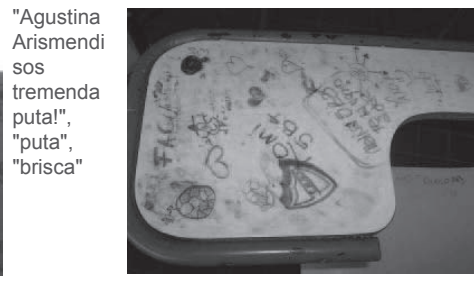

LD, salón 13, banco al.
Fotografía 69

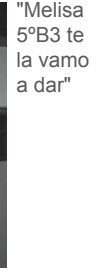

LC, salón 1, mesa al.

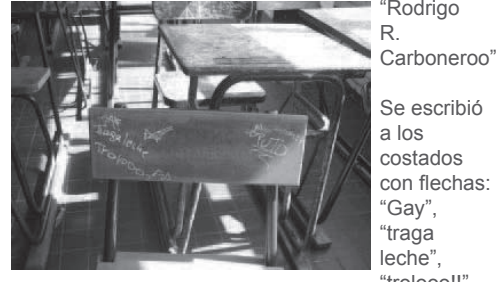

"trolooo!!" y "No existís!!" "Puto"

Estos graffitis intentan agredir, someter y destruir a la víctima. Consisten en insultos y a veces amenazas, con la finalidad de dejarla públicamente en un mal lugar. Muchos de los graffitis ya analizados incluyen insultos, como ocurre en los de índole sexual y deportiva. Pero lo que ocurre con estos graffitis de hostigamiento es que suelen incluir nombre y apellido de la víctima, crudo y desnudo, y el grupo al que pertenece. O, por ejemplo, son inscriptos en el banco en que se sienta el hostigado. 
Acosador y víctima son las dos caras inseparables del fenómeno del hostigamiento. Por eso, quizá, en algunos casos, los graffitis hostigadores constituyen el otro lado de la moneda de los graffitis de grito de dolor o de amor luego de una ruptura.

¿Cómo reconocer cuando se está ante una situación de hostigamiento escolar?, ¿qué actitud debemos tomar los profesores ante estas situaciones? Dan Olweus (1998), especialista en este tema, proporciona una guía para la identificación de posibles víctimas y agresores, y describe un programa de intervención en el que participó. Brevemente puede decirse que el objetivo del hostigador o grupo de hostigadores es intimidar o dañar intencionalmente a la otra persona, la o las víctimas, e implica un gran menosprecio hacia la dignidad como persona de esta/s última/s. Es común que el estudiante hostigado experimente nerviosismo, insomnio, terror de asistir al liceo, e incluso tenga pensamientos o intentos de suicidio. Por su parte, el hostigador suele presentar alguna psicopatología, demostrando falta de empatía y de responsabilidad con respecto a su conducta.

\section{Conclusiones generales}

"Es bien sabido que lo que hace al graffiti no es, a decir verdad, ni la inscripción ni su mensaje; es el muro, el fondo, la mesa. A causa de que el fondo existe plenamente, como un objeto que ya ha tenido vida, la escritura se le añade siempre como un suplemento enigmático: lo que está de más, de manera

supernumeraria, fuera de lugar, eso es lo que turba el orden; o mejor, en la medida en que el fondo no está limpio, es impropio para el pensamiento (lo contrario de la hoja blanca del filósofo), y por tanto resulta apropiado para todo lo demás (el arte, la pereza, la pulsión, la sensualidad, la ironía, el gusto; todo lo que el intelecto puede lamentar como otras tantas catástrofes estéticas"

(Barthes, Lo obvio y lo obtuso, 1986,).

El graffiti conforma una trama que cubre en su totalidad el liceo. No se trata de una trama uniforme, ni pareja, sino de un conjunto de hilos entrecruzados, enlazados, atravesados, superpuestos, y a veces deshilachados. Es una trama en continuo movimiento, que se va tejiendo y destejiendo, de forma subterránea, y por diversas voces. En palabras de Barthes, es el "suplemento enigmático" que se añade a las paredes, a los bancos, a las puertas y pizarrones del liceo "turbando" el orden, porque se incorpora a un fondo que ya tenía sentido y vida de por sí.

De la amplitud y riqueza de los datos empíricos obtenidos pudieron establecerse algunas categorías interpretativas, en las cuales se ha centrado este artículo. Los graffitis comprendidos en cada una de ellas tienen su función específica, diferente de la de las demás.

Todos estos graffitis "conviven" y "rivalizan" en el interior del liceo. No se trata de una, sino de múltiples voces. Pueden tener el formato de textos, símbolos, dibujos o pinturas, así como también de esténciles y stickers. Asimismo, son graffitis hechos con los más diversos elementos de producción y en los lugares más inesperados de los liceos relevados.

Podría decirse que el graffiti se constituye como un espacio de "libertad intersticial" para los alumnos, pues se "cuela" por los "intersticios" que quedan libres, generando un espacio de poder, el que, asimismo, se sustenta en las características propias del graffiti. 
A partir de lo dicho por alumnos y profesores, se han establecido algunas "fuentes" o "móviles" de los que surgiría la necesidad en los estudiantes de realizar graffitis en los liceos: aburrimiento, catarsis, necesidad de ser escuchado, diversión, autoafirmación, desplazamiento, intento de dejar una huella, thanatos, contagio, y comunicación con los pares, que varían según el tipo de graffiti del cual se trate.

Los profesores reconocen algunas temáticas que se repiten en los graffitis, así como algunas motivaciones que llevan a su realización. Pero ya casi no "ven" el graffiti, pese a su presencia abrumadora. Se ha intentado esbozar una interpretación de este fenómeno por medio de lo que se ha llamado "saturación" y "protección" a través de la negación. En primer lugar, los docentes se encuentran saturados ante un mismo "juego" que se repite una y otra vez. El graffiti presenta esa paradoja: choca, pero también satura y embota los sentidos. En segundo lugar, podría hablarse de la existencia en los docentes de un mecanismo de "protección" por medio de la negación, del no ver. Según el psicoanálisis, la instancia psíquica del Yo cuenta con mecanismos de defensa para hacer inconsciente aquello que podría desestructurarlo, con el objetivo de mantener su organización. Ciertas inscripciones encontradas en los liceos agreden directamente a los profesores; otras ponen de manifiesto una crisis en la escuela y en la sociedad en general, en la que el propio profesor está inmerso. Este punto es abordado con mayor profundidad en la tesis de maestría. Allí también se mencionan algunas experiencias que se han realizado en los liceos con respecto a los graffitis. En la mismas se aborda la relación entre las tribus urbanas y el graffiti, tratándose específicamente las siguientes tribus, que surgieron con esas denominaciones en el marco del propio estudio: hippies, punks, planchas, chetos, góticos, floggers, hip-hoperos, rastas y emos.

Esta investigación, si bien no exhaustiva, ha permitido un importante acercamiento al fenómeno del graffiti. También abre nuevas "puertas" en torno a algunas cuestiones e interrogantes para seguir profundizando en futuras investigaciones:

- ¿Qué hacer ante los graffitis en los liceos?, ¿de qué forma abordarlos?. Desde la perspectiva en que se ha basado esta investigación, "leer" y "escuchar" los graffitis en el liceo permite al docente, por un lado, lograr un conocimiento más profundo de su estudiantado, y tender puentes para una mejor comunicación; y por otro lado, reflexionar en torno a algunos problemas (evaluación, crisis de la escuela, etc.).

- ¿Cómo intervenir específicamente ante algunos graffitis que en este estudio se han incluido bajo las denominaciones de "el grito", "la fobia", "el hostigamiento", o que manifiestan violencia de algún tipo?

- ¿Cuál es la perspectiva de la dirección de las instituciones educativas ante el graffiti?, ¿cómo actúa ante situaciones en que se descubre haciendo un graffiti "in fraganti" a un estudiante?

- ¿El graffiti es arte? Si así fuera, ¿en qué casos sería una expresión artística y en cuáles no?

- ¿Hay una relación más cercana entre estudiantes de la orientación artística y graffiti (en relación a alumnos de otras orientaciones)?

\section{Citas bibliográficas}

- Bauman, Z. 2008. Vida de consumo. Buenos Aires: FCE.

- Cortina, A. "Aporofobia". En: El País, 07 de Marzo de 2000.

- Díaz Barriga, Á. 1995. Docente y programa. Lo institucional y lo didáctico. $2^{a}$ ed. Buenos Aires: Aique.

- Fabra, M.; Domènech, M. 2001. Hablar y escuchar. Barcelona: Paidós.

- Gadamer, H. 2005. Verdad y método I. 11a ed. Salamanca: Sígueme.

- Gándara, L. 2005. Graffiti. Buenos Aires: Eudeba.

- Huizinga, J. 1990. Homo ludens. Madrid: Alianza/Emecé.

- Jackson, P. 2001. La vida en las aulas. $6^{\mathrm{a}}$ ed. Madrid: Morata. 
- Kozak, C. 2004. Contra la pared: sobre graffitis, pintadas y otras intervenciones urbanas. Buenos Aires: Libros del Rojas.

- Le Bon, G. 2000. Psicología de las masas. $5^{a}$ ed. Madrid: Morata.

- Litwin, E. 1998. "La evaluación: campo de controversias y paradojas o un nuevo lugar para la buena enseñanza", en Camilloni, A.; et al. Estudios culturales y comunicación. Análisis, producción y consumo cultural de las políticas de identidad y posmodernismo. Buenos Aires: Paidós.

- Mèlich, J. 1998. Antropología simbólica y acción educativa. Barcelona: Paidós.

- Zarranz; L.; et al. Entrevista a Eduardo Galeano: "Toda riqueza se nutre de alguna pobreza". Mar del Plata, 26 de diciembre de 2008 [online] [Consultado 12 de marzo de 2009] Disponible en Internet: <www.ts.ucr.ac.cr/binarios/reconcep/reconc-00322.pdf>

\section{Bibliografía}

- Barthes, R. 1986. Lo obvio y lo obtuso. Imágenes, gestos, voces. Barcelona: Paidós.

- Bruner, J. 1997. La educación, puerta de la cultura. Madrid: Visor.

- Bruner, J. 1998. Actos de significado. Más allá de la revolución cognitiva. $3^{a}$ ed. Madrid: Alianza.

- Charlot, B. 2008. La relación con el saber, formación de maestros y profesores, educación y globalización. Cuestiones para la educación de hoy. Montevideo: Trilce.

- Gadamer, H. 2006. Verdad y método II. 7a ed. Salamanca: Sígueme.

- Gadamer, H. 2007. El giro hermenéutico. $3^{a}$ ed. Madrid: Cátedra.

- Litwin, E. 2008. El oficio de enseñar: condiciones y contextos. Buenos Aires: Paidós.

- Martínez, E. 2002. "Aporofobia”, en Conill, J. (coord.), Glosario para una sociedad intercultural, Valencia: Bancaja.

- Olweus, D. 1998. Conductas de acoso y amenaza entre escolares. Madrid: Morata.

- Santos Guerra, M. 2005. Valor de cambio [online] [Consultado 7 de marzo de 2011] Disponible en Internet: <http://blogs.opinionmalaga.com/eladarve/2005/06/18/valor-de-cambio/>

- Scheines, G. 1998. Juegos inocentes, juegos terribles. Buenos Aires: Eudeba.

- Tragedia en Carmen de Patagones. En: El Clarín, 29 de septiembre de 2004.

\section{Notas}

${ }^{1}$ En Uruguay se denomina "liceos" a las instituciones de enseñanza media.

${ }^{2}$ Es importante realizar algunas precisiones en relación al uso del término graffiti en la presente investigación:

- se emplearán los términos graffiti para el singular y graffitis para el plural, siguiendo el uso más corriente en el ámbito rioplatense, aunque en italiano graffiti abarca tanto el singular como el plural (graffito se usa para los graffitis de la antigüedad).

- Se mantendrá la doble "f" en la escritura de la palabra graffiti, por constituir la forma más divulgada en el ámbito cultural, aunque la palabra ha sido castellanizada y puede ser escrita con una sola "f".

${ }^{3}$ En Argentina se le denomina "machete", y en España "chuleta".

${ }^{4}$ El conocimiento académico consta de "valor de uso" cuando genera interés por sí mismo, motiva, es aplicable, responde a las necesidades cognitivas y vitales, y ayuda a mejorar. Por el contrario, tiene "valor de cambio" cuando, al demostrarse su adquisición, puede ser canjeado por una calificación, sin importar si tiene o no "valor de uso". 
${ }^{5}$ Abreviaturas: Al.: Alumno / G.F.: Grupo focal / Prof.: Profesor

${ }^{6}$ El término "plancha" para designar a esta tribu urbana tiene su origen en el año 2002, en Uruguay. Posiblemente haga referencia a la plancha de fotos de los delincuentes que toma la policía. Es similar a la tribu de los "cumbieros" en Argentina.

7 "Si alguien encontró el sentido de la vida, favor de escribirlo aquí [.....]", "Welcome, my son. Welcome...t o the machine. Pink Floyd", y "Lo más sensato que podemos hacer los seres humanos es suicidarnos".

* El Artículo se enmarca en la tesis de maestría de la autora: "Escuchar las paredes del liceo: hermenéutica del graffiti”, dirigida por la Mag. Gabriela Augustowsky. Año 2010.

** Máster en Educación y Diploma en Educación, Universidad ORT Uruguay. Profesora de Filosofía de Enseñanza Media, Instituto de Profesores Artigas. Diseñadora Gráfica, Universidad del Trabajo del Uruguay. 